\title{
NIF Ambient Vibration Measurements
}

\author{
C.R. Noble, M.S., Hoehler, S.C. Sommer
}

November 29, 1999

U.S. Department of Energy

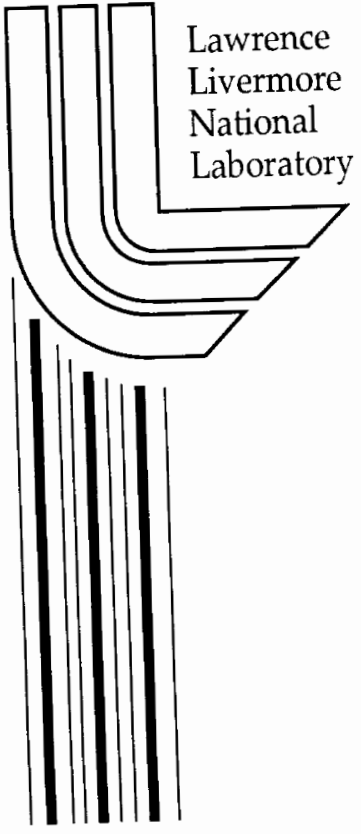




\section{DISCLAIMER}

This document was prepared as an account of work sponsored by an agency of the United States Government. Neither the United States Government nor the University of California nor any of their employees, makes any warranty, express or implied, or assumes any legal liability or responsibility for the accuracy, completeness, or usefulness of any information, apparatus, product, or process disclosed, or represents that its use would not infringe privately owned rights. Reference herein to any specific commercial product, process, or service by trade name, trademark, manufacturer, or otherwise, does not necessarily constitute or imply its endorsement, recommendation, or favoring by the United States Government or the University of California. The views and opinions of authors expressed herein do not necessarily state or reflect those of the United States Government or the University of California, and shall not be used for advertising or product endorsement purposes.

This work was performed under the auspices of the U. S. Department of Energy by the University of California, Lawrence Livermore National Laboratory under Contract No. W-7405-Eng-48.

This report has been reproduced directly from the best available copy.

Available electronically at http://www.doe.gov/bridge

Available for a processing fee to U.S. Department of Energy and its contractors in paper from

U.S. Department of Energy Office of Scientific and Technical Information P.O. Box 62

Oak Ridge, TN 37831-0062

Telephone: (865) 576-8401

Facsimile: (865) 576-5728

E-mail: reports@adonis.osti.gov

Available for the sale to the public from

U.S. Department of Commerce

National Technical Information Service

5285 Port Royal Road

Springfield, VA 22161

Telephone: (800) 553-6847

Facsimile: (703) 605-6900

E-mail: orders@ntis.fedworld.gov

Online ordering: http://www.ntis.gov/ordering.htm

\section{OR}

Lawrence Livermore National Laboratory

Technical Information Department's Digital Library

http://www.Ilnl.gov/tid/Library.html 


\title{
NIF Ambient Vibration Measurements
}

\section{A Summary of Acceleration Data Acquired During the Spring and Summer of 1999}

\author{
Charles R. Noble ${ }^{\dagger}$ \\ Matthew S. Hoehler ${ }^{\dagger}$ \\ Stanley C. Sommer ${ }^{\text {sh }}$ \\ ${ }^{\dagger}$ New Technologies Engineering Division \\ Lawrence Livermore National Laboratory \\ ${ }^{8}$ Laser Science Engineering Division \\ Lawrence Livermore National Laboratory
}

\subsection{Overview}

LLNL has an ongoing research and development project that includes developing data acquisition systems with remote wireless communication for monitoring the vibrations of large civil engineering structures. In order to establish the capability of performing remote sensing over an extended period of time, the researchers needed to apply this technology to a real structure. The construction of the National Ignition Facility provided an opportunity to test the data acquisition system on a large structure to monitor whether the facility is remaining within the strict ambient vibration guidelines.

This document will briefly discuss the NIF ambient vibration requirements and summarize the vibration measurements performed during the Spring and Summer of 1999. In addition, a brief description of the sensors and the data acquisition systems will be provided in Appendix B.

\subsection{NIF Vibration Requirements}

Before construction began at the NIF site, a conservative representation of the broadband free-field ambient vibration power spectral density (PSD) environment was developed as discussed in memo NIF-0003354. This acceleration environment was primarily due to operations at adjacent facilities (such as U-AVLIS), ground vehicular traffic, nearby construction activities (such as the Mixed Waste Treatment Facility), underground utility systems, and wind. After extensive evaluations of all the potential vibration sources that will be installed as part of NIF (such as axial fans, pumps, chillers, boilers, and utility piping), the top-of-foundation ambient vibration PSD spectrum was defined in SSDR 1.2.2.1 for 
Conventional Facilities as $1 \times 10^{-10} \mathrm{~g}^{2} / \mathrm{Hz}$ ( 1 to 200 hertz) and the top-of-foundation ambient vibration PSD broadband spectrum was developed in memo NIF-0004049 for Title II evaluations of Special Equipment as $2 \times 10^{-11} \mathrm{~g}^{2} / \mathrm{Hz}$ for 2 to 70 hertz and $1 \times 10^{-10} \mathrm{~g}^{2} / \mathrm{hz}$ for 80 to 200 hertz. Consistent with this broadband acceleration spectrum, a narrowband displacement limit at the top- of-foundation of 0.01 microns was developed for single-harmonic vibration sources, such as at the operating speed of mechanical equipment. The broadband and narrowband vibration requirements applied to the laser bay, switchyard, and target bay foundations supporting alignment-sensitive equipment. A broadband vibration requirement that was several orders of magnitude larger than that for the laser bay foundations was defined in SSDR 1.2.2.3 for the Optics Assembly Building (OAB) as $1 \mathrm{x}$ $10^{-8} \mathrm{~g}^{2} / \mathrm{Hz}$ ( 1 to 200 hertz).

In CSP-6/10 and CSP-9, the Section 15 specifications for the mechanical equipment require both factory and field testing to vibration limits consistent with the broadband and narrowband limits discussed in memo NIF-0004049. After the equipment successfully satisfies the factory vibration test requirements, such as $0.03 \mathrm{~g}$ acceleration limit, the equipment is being installed and operated at the NIF site. The first set of equipment that are sources of vibration to be installed and operated at the NIF site is the equipment in the Central Plant. As outlined in the "72-Hour Test Schedule", the Central Plant equipment includes 3 chillers, 3 primary chilled water pumps, 3 secondary chilled water pumps, 4 cooling tower fans, 4 water filter pumps, 4 conditioning water pumps, 2 boilers, and 2 hot water pumps. Except for the cooling tower equipment and two of the chillers, the factory vibration test results of all the rotating equipment were approved by Parsons. As the mechanical equipment was activated in the Central Plant, LLNL measurements of ambient vibrations were performed in order to characterize the vibration environment at the site. These type of measurements will continue as other vibration sources are activated so that a phased comparison of the effects of different sources can be made. It is expected that as more sources of vibration are activated, the difference in PSD magnitude between the Title II top-of-foundation spectrum and the site measurements will be reduced.

\subsection{Description of Data Acquisition Systems}

To perform the ambient vibration measurements, there were two data acquisition systems (DAS) operating at NIF during the Spring and Summer of 1999. One data acquisition system operated on the interferometer isolated slab in the Optics Assembly Building (OAB) (See Figures 1 through 4), while the other system was located in the Central Plant (See Figures 1 through 2 and Figures 5 through 8). The OAB system was equipped with a 3 channel GSR-18 Terra Technology recorder and one Wilcoxon 731A triaxial piezoelectric accelerometer. The sensitivity of the accelerometer is $10 \mathrm{~V} / \mathrm{g}$ and it has a frequency response of 1 to $87 \mathrm{hz}$ for accelerations up to $0.5 \mathrm{~g}$. It should be noted that some of the data recorded at the NIF OAB, such as the recording shown in Figure 9c for Monday August 2 at 3:00 p.m., exhibited peculiar behavior when the power spectral density mag-

nitude dropped below $1 \times 10^{-13} \mathrm{~g}^{2} / \mathrm{Hz}$. It was concluded that the low level of vibration was probably at the noise level of either the sensor or the recorder. The unique feature of 
this DAS is its ability for remote wireless communication. With this DAS, the measured data is retrieved using the laptop away from the measurement site rather than continually making trips to the structure being monitored. For a technical description of this system, see Appendix B.

The data acquisition system located in the Central Plant was equipped with a 6 channel RT72-A02 Refraction Technology recorder and two S6000 triaxial accelerometers. The accelerometers have a sensitivity of $120 \mathrm{~V} / \mathrm{m} / \mathrm{s}$ and the frequency response is $2 \mathrm{~Hz}-90 \mathrm{~Hz}$. One accelerometer was located on the isolated slab for chiller 200-RCHC-1-1 and one on the plant slab near chiller 200-RCHC-1-1 (See Figures 2 and 7). This DAS did not have the capability for wireless communication. In addition, the system was equipped with solar panels to recharge the batteries powering the DAS. Problems with the panels arose when they were not subjected to enough sunlight. For example, due to the lack of good weather during the week of the 72-hour test at the Central Plant and the location of the solar panel, the batteries only had enough power to take measurements on August 3rd and 4 th at 3:00 p.m.

\subsection{NIF Ambient Vibration Measurements}

For the Central Plant mechanical equipment, two different series of LLNL measurements were performed to evaluate the vibration levels at the Central Plant and on an isolated slab in the OAB. Vibration measurements were not performed in the laser bays, switchyards, or target bay due to the heavy construction occurring in those locations. The first series of LLNL measurements were performed during the CSP-9 field testing of the Central Plant equipment on July 7 th - 9 th. For these measurements, there was not an attempt to correlate the timing of the measurements with the operation of specific equipment. For the CSP-9 field tests of the pumps, boilers, chillers, and cooling tower fans, the test procedures provided in Appendix $\mathrm{C}$ were used. These test procedures were identical to those used for the factory testing and were approved by Parsons during the submittal process for the CSP-9 Section 15 specifications. Several relatively small pumps that serve the Cooling Tower filtration system and are not vibration isolated were identified during the field testing. Field tests of the vibration levels from those pumps and motors were also performed. The field vibration tests of the Central Plant mechanical equipment were performed by David Poffenbarger for Marelich Mechanical. Vibration levels in three orthogonal directions were measured in terms of accelerations above the four springs at the equipment skid. In addition, vibration levels were measured at the foreword and backward motor bearing locations. For Marelich informational purposes, vertical vibration levels were measured below the four springs at the equipment skid. The results of the field vibration tests were submitted to Parsons for their review and are not discussed in this report.

The second series of LLNL measurements were performed during the 72-hour test of the Central Plant on August 2nd - 5th. For these measurements, an attempt was made to correlate the timing of the measurements with the operation of specific equipment. Due to problems with the solar panels as discussed earlier, measurements in the Central Plant were only collected on August 3rd and 4th at 3:00 p.m. and Table 1 lists the Central Plant 
equipment that was operating at that time. Unfortunately, the chiller by which the sensors were located was not operating at 3:00 p.m. on either August 3rd or 4th. The sensors located in the $\mathrm{OAB}$ recorded vibration levels at three different times on August 2nd, 3rd, and 4th. Figures 9 through 11 show the results of LLNL vibration measurements on August 2nd, 3rd, and 4th, while Figures 13 through 18 show the results of LLNL vibration measurements on July 8th and 9th.

Table 1: Central Plant Operating Test Schedule

\begin{tabular}{|c|c|c|}
\hline $\begin{array}{c}\text { Central Plant Mechanical } \\
\text { Equipment }\end{array}$ & $\begin{array}{c}\text { August 3, } \\
1999 \\
3: 00 \mathrm{PM}\end{array}$ & $\begin{array}{c}\text { August 4, } \\
1999 \\
3: 00 \mathrm{PM}\end{array}$ \\
\hline \hline Chiller 200-RCHC-1-1 & no & no \\
\hline Chiller 200-RCHC-2-1 & no & yes \\
\hline Chiller 200-RCHC-3-1 & yes & no \\
\hline Pump 200-PCHW-52-1 & no & yes \\
\hline Pump 200-PCHW-53-1 & yes & no \\
\hline Pump 200-PCHW-56-1 & no & yes \\
\hline Pump 200-PCHW-57-1 & yes & no \\
\hline Cooling Tower Fan 300-CT-3-1 & yes & yes \\
\hline Pump 300-PCT-3-1 & yes & yes \\
\hline Boiler 200-BHW-1-A & yes & no \\
\hline Boiler 200-BHW-2-A & no & yes \\
\hline Pump 200-BHW-1-A & yes & no \\
\hline Pump 200-BHW-2-A & no & yes \\
\hline
\end{tabular}

There are several trends in most of the acceleration PSD in Figures 9, 12, 14, and 15. First, the maximum acceleration magnitudes recorded on the $\mathrm{OAB}$ interferometer isolated slab in the longitudinal, transverse, or vertical direction is less than $1 \times 10^{-10} \mathrm{~g}^{2} / \mathrm{Hz}$ with the nominal value near $1 \times 10^{-12} \mathrm{~g}^{2} / \mathrm{Hz}$. This relatively low level of vibration is near the floor of the sensitivity range of the vibration sensors which explains some of the frequency content, or noise, below $1 \times 10^{-13} \mathrm{~g}^{2} / \mathrm{Hz}$, as discussed earlier. These vibration levels are greater than those recorded in May and June 1998 as summarized in memo NIF-0013691. Since there were no permanent vibration sources at the NIF site in May and June 1998, the vibration results recorded in 1999 demonstrate the effects of the Central Plant equipment. Since the vibration requirement for the $\mathrm{OAB}$ isolated slab is $1 \times 10^{-8} \mathrm{~g}^{2} / \mathrm{Hz}$, the effects of the Central Plant equipment are acceptably minimized before reaching the $\mathrm{OAB}$ and there is margin to account for the effects of vibration sources in the $\mathrm{OAB}$, such as the cleanroom 
fans and utility systems. As the cleanroom fans are activated in the $\mathrm{OAB}$, additional vibration measurements will be performed on the isolated slabs to evaluate their effects.

The second trend is that the maximum acceleration magnitudes recorded on the Central Plant foundations in the longitudinal, transverse, or vertical direction have vibration spikes at 30 and 60 hertz that reach $1 \times 10^{-8} \mathrm{~g}^{2} / \mathrm{Hz}$, while the nominal value is between $1 \times 10^{-11}$ $\mathrm{g}^{2} / \mathrm{Hz}$ and $1 \times 10^{-10} \mathrm{~g}^{2} / \mathrm{Hz}$ (See Figures 10, 13, and 17). Even though these acceleration levels are close to the top-of-foundation requirements for the laser bay, switchyard, and target bay foundations, the distance between those foundations and the Central Plant will serve as a vibration mitigation path. For the measurements on August 3rd and 4th, the third trend is that the vibration levels on the chiller pad are less than those on the plant (main) slab (See Figures 10 and 11). Since chiller 200-RCHC-1-1 was not operating during those measurements, it is expected that the thicker chiller pad has lower vibration levels than the plant slab. As summarized in a letter dated September 3, 1999, Parsons is planning to perform analytical predictions of the effects of vibrations at the Central Plant on the laser bay foundations, using the results of field vibration tests of the Central Plant mechanical equipment. In addition to these analyses, vibration measurements will be performed on the laser bay foundations.

A measure of the energy content of the PSD spectra is the root-mean-square (RMS) value of the spectra, or the area of the spectra. The RMS values for Figures 9 through 11 are provided in Tables 3 through 6 and Table 2 provides a comparison of the measured RMS values with the RMS values for the NIF vibration requirements. In Table 2, the RMS values are computed for a frequency range of 1 to 80 hertz and the requirements for the Central Plant are actually the requirements for the laser bay foundations because there are no explicit requirements for the Central Plant foundations. The values in Table 2 indicate there is significant margin between the measured values and the $\mathrm{OAB}$ requirements and the levels in the Central Plant are similar to the requirements for the laser bay foundations. The margin between the Central Plant measured values and the Laser Bay requirements will be due to the vibration mitigation path and will be reduced as further vibration sources are activated at the NIF site.

Table 2: Summary of Acceleration RMS Values

\begin{tabular}{|c|c|c|}
\hline & $\begin{array}{c}\text { OAB Isolated } \\
\text { Slab }(\mu \mathrm{g})\end{array}$ & $\begin{array}{c}\text { Central Plant } \\
(\mu \mathrm{g})\end{array}$ \\
\hline \hline SSDR 1.2.2.1 & N/A & 88.9 \\
\hline Title II Requirement & N/A & 42.1 \\
\hline SSDR 1.2.2.3 & 888.8 & N/A \\
\hline $8 / 02 / 99$ longitudinal maximum & 4.8 & N/A \\
\hline $8 / 03 / 99$ longitudinal maximum & 43.1 & 81.7 \\
\hline $8 / 04 / 99$ longitudinal maximum & 15.5 & 103.8 \\
\hline
\end{tabular}


Table 2: Summary of Acceleration RMS Values

\begin{tabular}{|c|c|c|}
\hline & $\begin{array}{c}\text { OAB Isolated } \\
\text { Slab }(\mu \mathrm{g})\end{array}$ & $\begin{array}{c}\text { Central Plant } \\
(\mu \mathrm{g})\end{array}$ \\
\hline \hline $8 / 02 / 99$ transverse maximum & 9.6 & N/A \\
\hline $8 / 03 / 99$ transverse maximum & 18.7 & 324.9 \\
\hline $8 / 04 / 99$ transverse maximum & 28.6 & 443.4 \\
\hline $8 / 02 / 99$ vertical maximum & 12.8 & N/A \\
\hline $8 / 03 / 99$ vertical maximum & 16.7 & 165.4 \\
\hline $8 / 04 / 99$ vertical maximum & 28.5 & 224.7 \\
\hline
\end{tabular}

\subsection{Conclusions}

The following conclusions can be made regarding the ambient vibration measurements taken at the National Ignition Facility during the Spring and Summer of 1999:

- LLNL researchers have demonstrated the ability to perform remote sensing of a large structure over an extended period of time. This technology paves the way for performing long-term structural health monitoring of a critical civil engineering structure. Moreover, the remote sensing capability was extremely useful for measurements in the $\mathrm{OAB}$, since the $\mathrm{OAB}$ was at Cleanroom Protocol 2 during the measurements and access was limited.

- Since the measured power spectral density of the OAB isolated slab is below the requirement of $1 \times 10^{-8} \mathrm{~g}^{2} / \mathrm{Hz}$, the vibration levels caused by the Central Plant equipment is minimized before reaching the $\mathrm{OAB}$. Therefore, there is some margin to allow for future vibration sources in the $\mathrm{OAB}$, such as cleanroom fans and utility systems.

- Although the vibration levels of the Central Plant are rather close to the top-of-foundation requirements for the laser bay, switchyard, and target bay foundations, the distance between the Central Plant and those foundations will serve as a vibration mitigation path.

- The vibration levels on the Central Plant chiller pad are less than those on the plant (main) slab. This is expected because the chiller 200 RCHC-1-1, which sits on the thick chiller pad, was not operating during the recorded measurement times.

- There is a notable margin between the measured RMS values and the requirements for the $\mathrm{OAB}$. This margin will be reduced as further vibration sources are activated at the NIF site.

- Further LLNL vibration measurements are being planned to monitor the vibration levels as future vibration sources are being added to the site. Additional measurements will also be performed on the laser bay foundations. 


\subsection{Acknowledgements}

This work was performed at the Lawrence Livermore National Laboratory under the auspices of the United States Department of Energy, contract W-7405-Eng-48.

\subsection{References}

1. Sommer, S.C., "Ambient Vibration Spectra for NIF", NIF-0003354, Lawrence Livermore National Laboratory, Livermore, California, September 22, 1997

2. "National Ignition Facility Subsystem Design Requirements, Laser \& Target Area Building (LTAB)", SSDR 1.2.2.1, NIF-0000319-OC, Livermore National Laboratory, Livermore, California, June 27, 1997

3. Sommer, S.C., "NIF Broadband and Narrowband Vibration Criteria", NIF-0004049, Lawrence Livermore National Laboratory, Livermore, California, December 1, 1997

4. "National Ignition Facility Subsystem Design Requirements, Optics Assembly Building (OAB)", SSDR 1.2.2.3, NIF-0000551-OD, Livermore National Laboratory, Livermore, California, September 29, 1997

5. "Specification OCS-0075, CSP-6, Target Area Building Shell at Livermore Site, National Ignition Facility", B345170, PFN NIF 97005, Parsons Infrastructure and Technology Group, Inc., Pasadena, California, March 24, 1998

6. "Specification OCS-0076, CSP-9, Laser Building Buildout, Site, \& Central Plant at Livermore Site, National Ignition Facility", B342773, PFN NIF 97005, Parsons Infrastructure and Technology Group, Inc., Pasadena, California, December 18, 1997

7. Hutchings, L. and Rock, D., "National Ignition Facility Vibration Study", NIF-0013691, Lawrence Livermore National Laboratory, Livermore, California, September 25, 1998

8. MacCalden, P.B., "Vibration Predictions on the NIF Foundations", Parsons Infrastructure \& Technology Group, Pasadena, California, September 3, 1999 


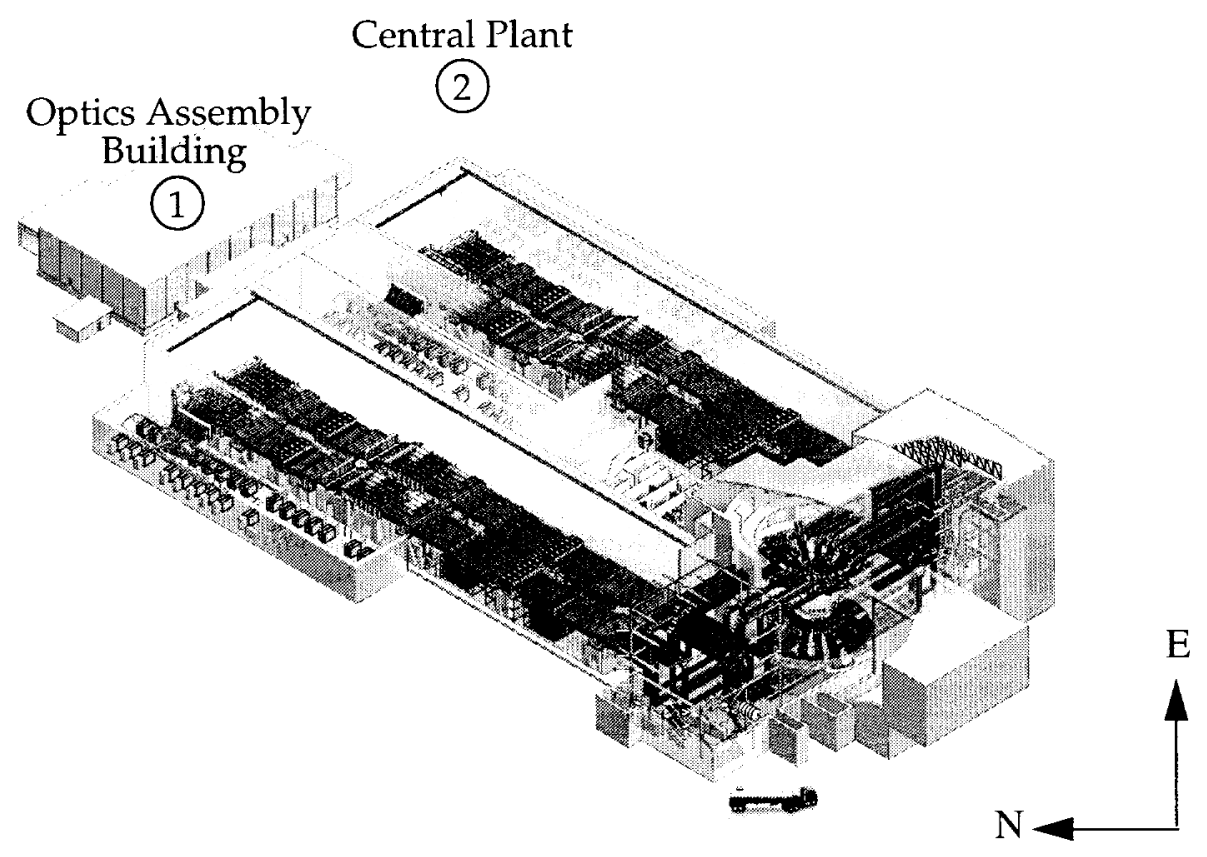

FIGURE 1. Data acquisition system locations at NIF

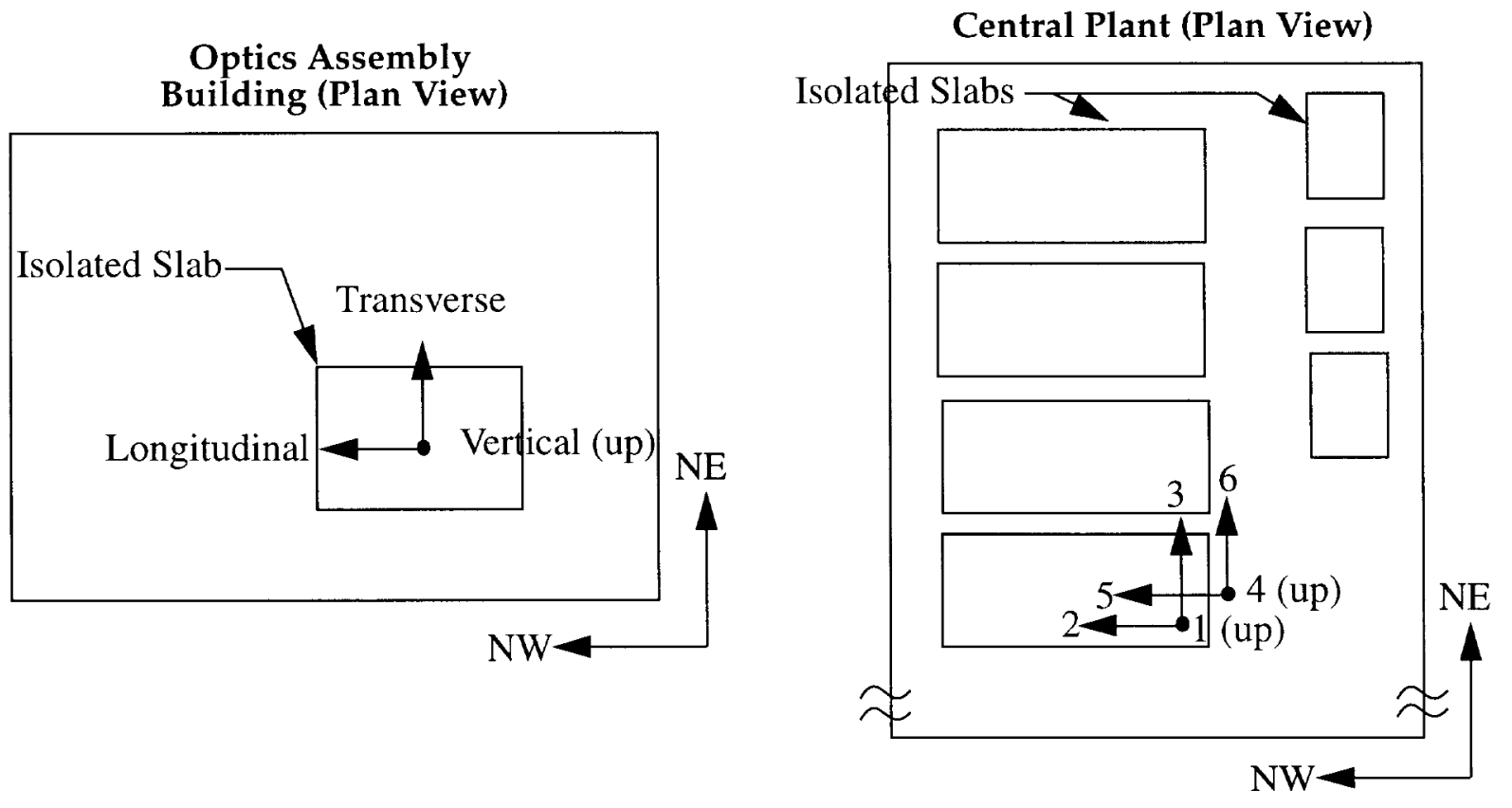

FIGURE 2. Channel numbering and orientation for DAS's 


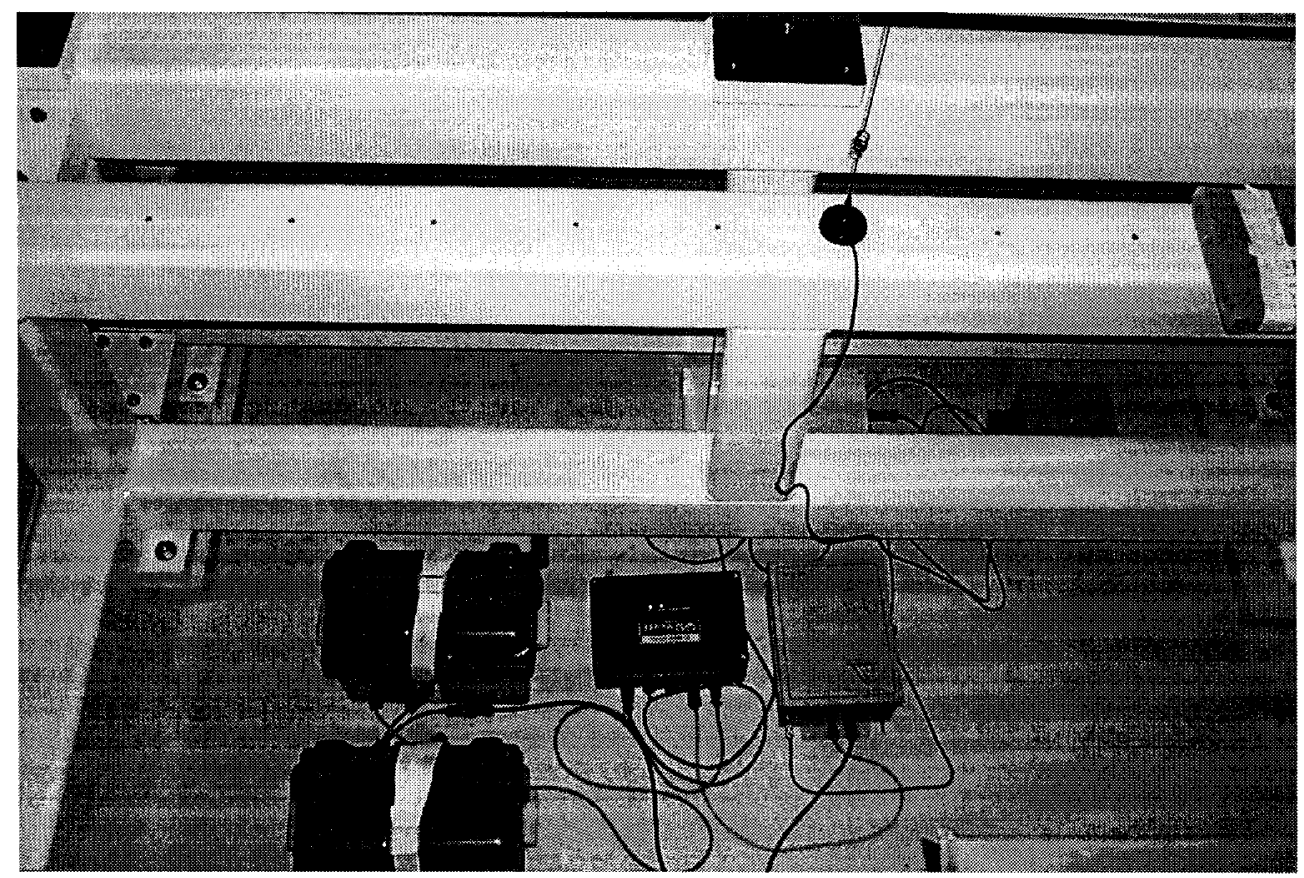

Figure 3. NIF OAB data acquisition system. Located from left to right are the two batteries, GSR-18 recorder, cellular communication, amplifiers, and accelerometers (located in back).

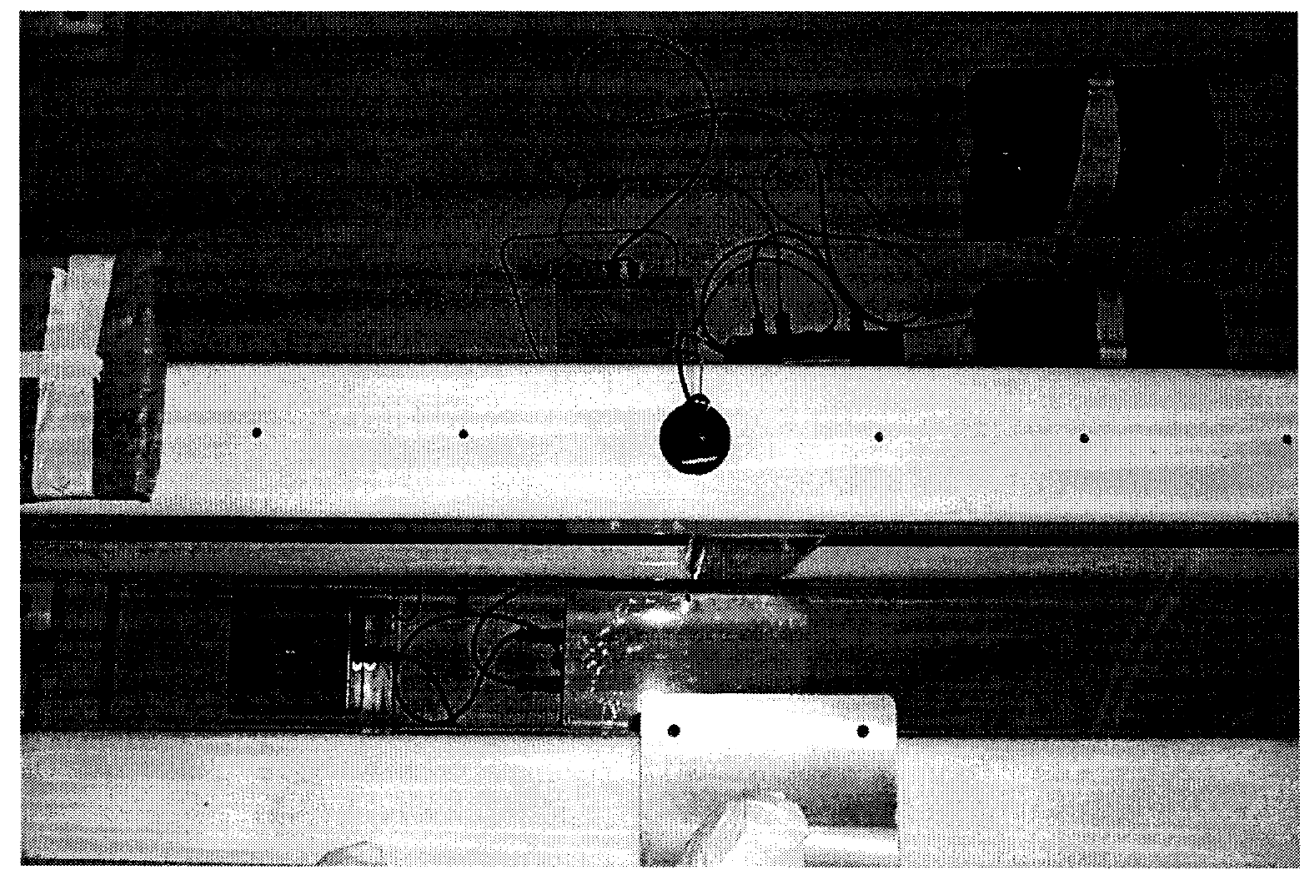

Figure 4. NIF OAB data acquisition system. Located in front (from left to right) are the accelerometers and amplifiers. Located in back (from left to right) is the cellular communication, GSR-18 recorder, and two batteries. 


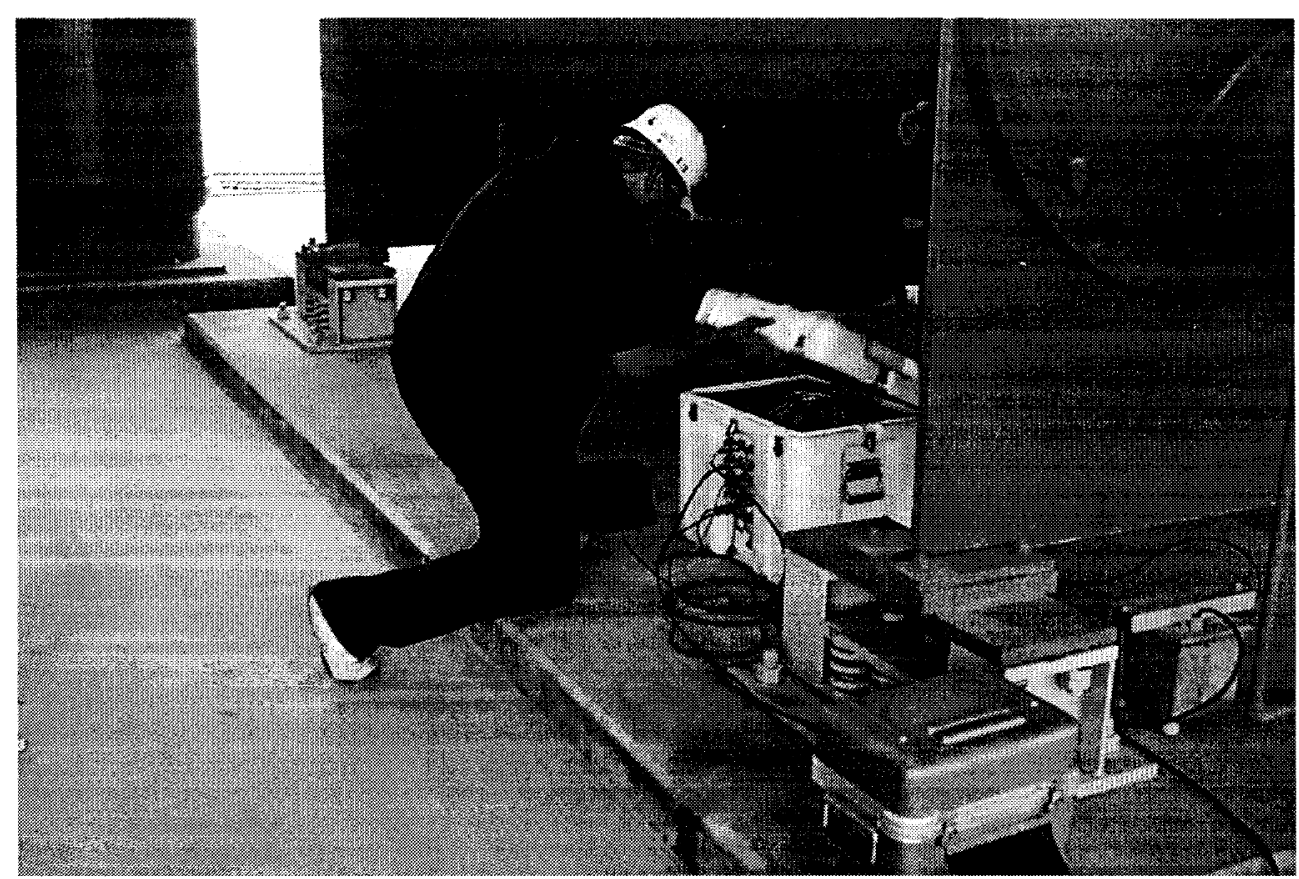

Figure 5. Central Plant data acquisition system. Pat Lewis is about to acquire the data from this system.

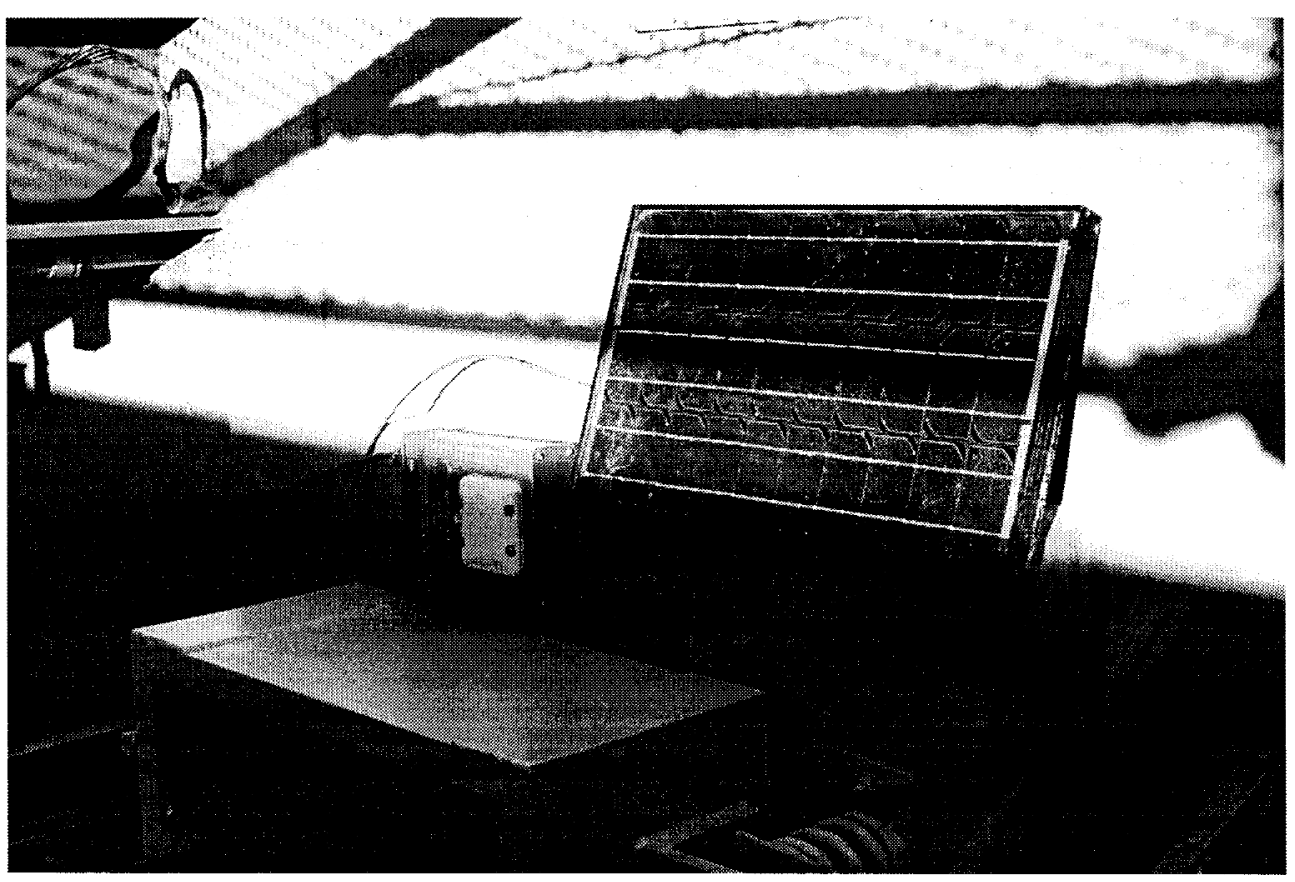

Figure 6. This is a picture of the solar panel that recharged the Central Plant data acquisition system. 


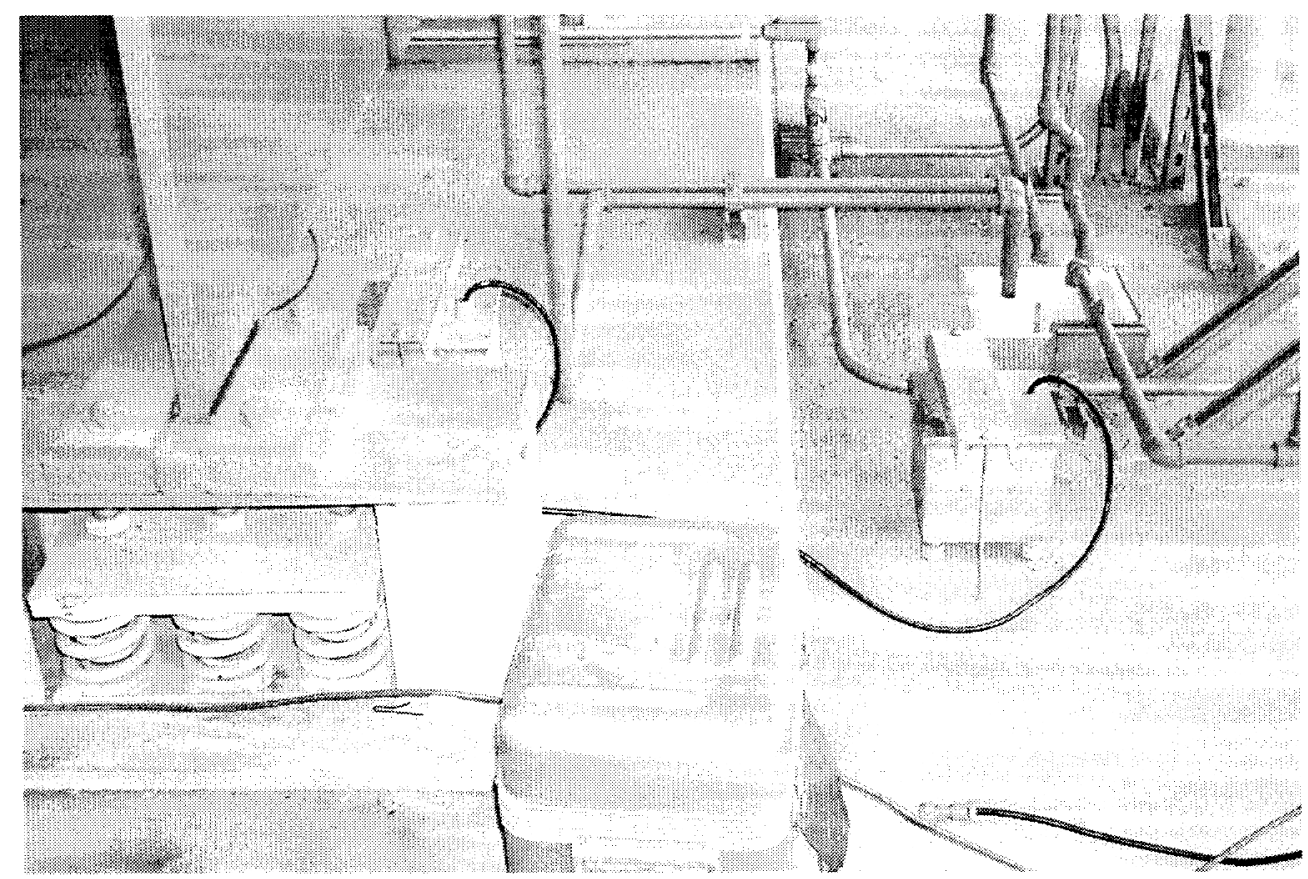

Figure 7. A photo of the two accelerometer packages, one on the chiller pad (channels 1, 2 , and 3) and one located on the plant slab (channels 4,5 , and 6), and the battery for the Central Plant data acquisition system.

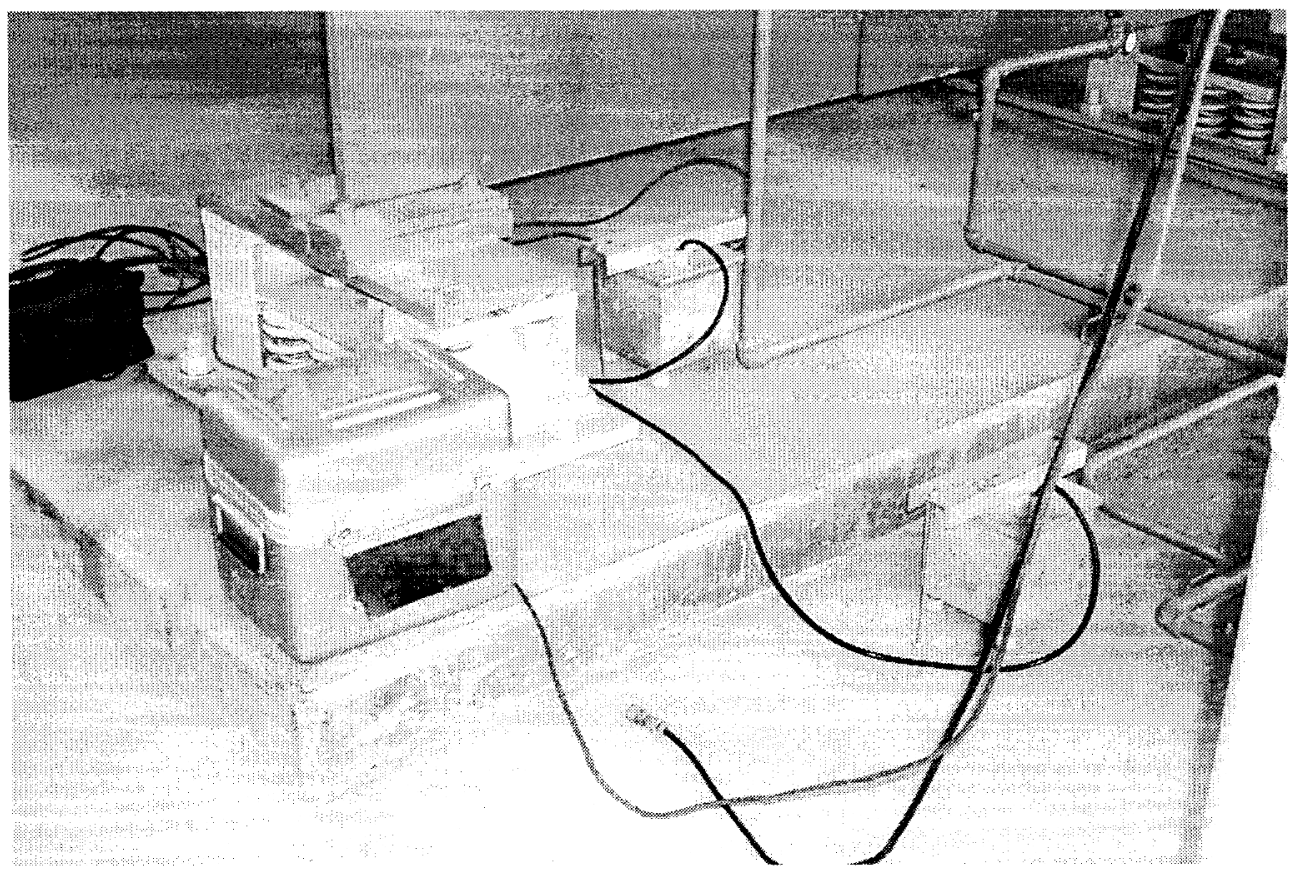

Figure 8. A photo of the two accelerometer packages and the battery for the Central Plant data acquisition system. 


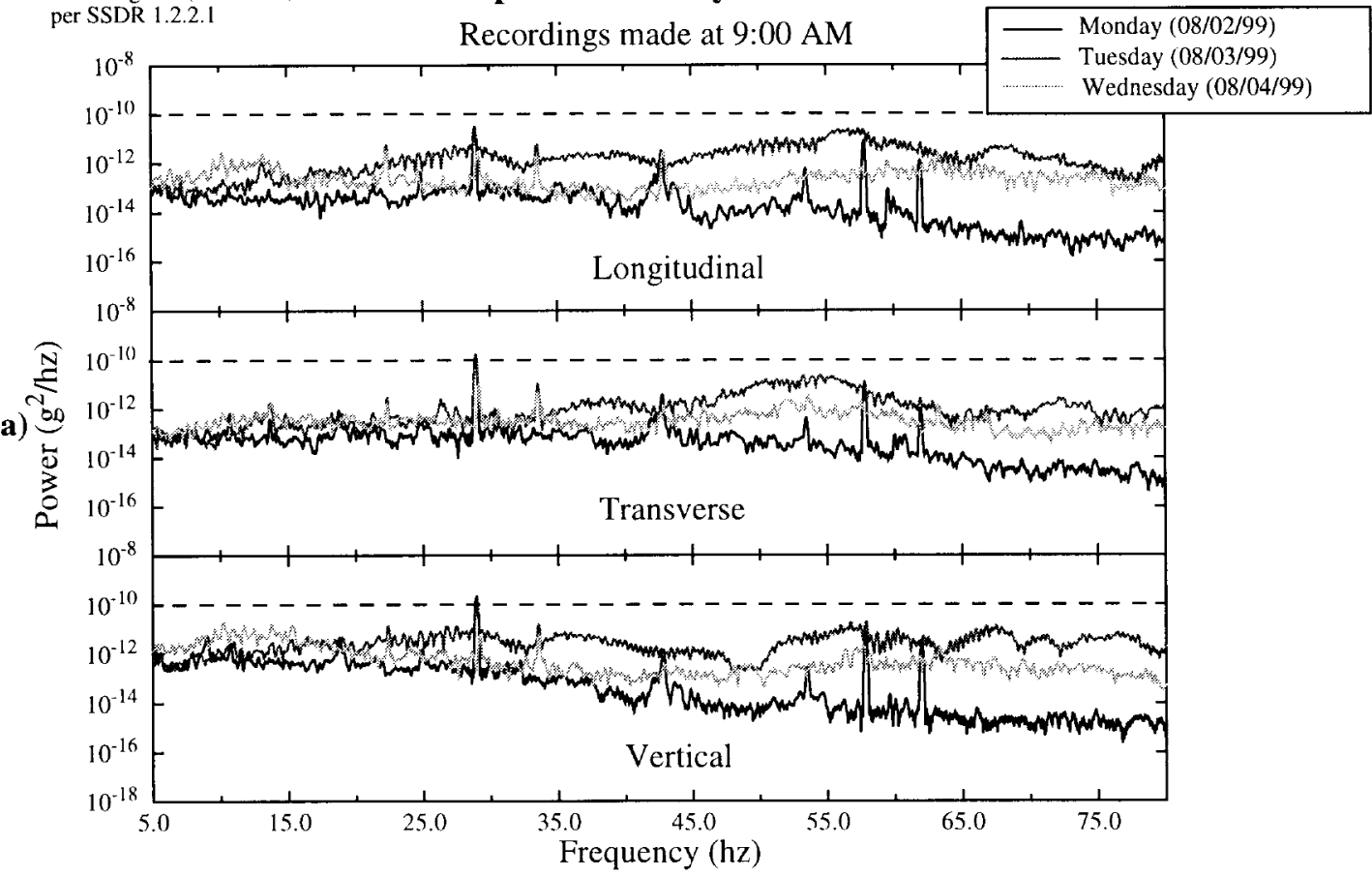

Conventional Facitlities

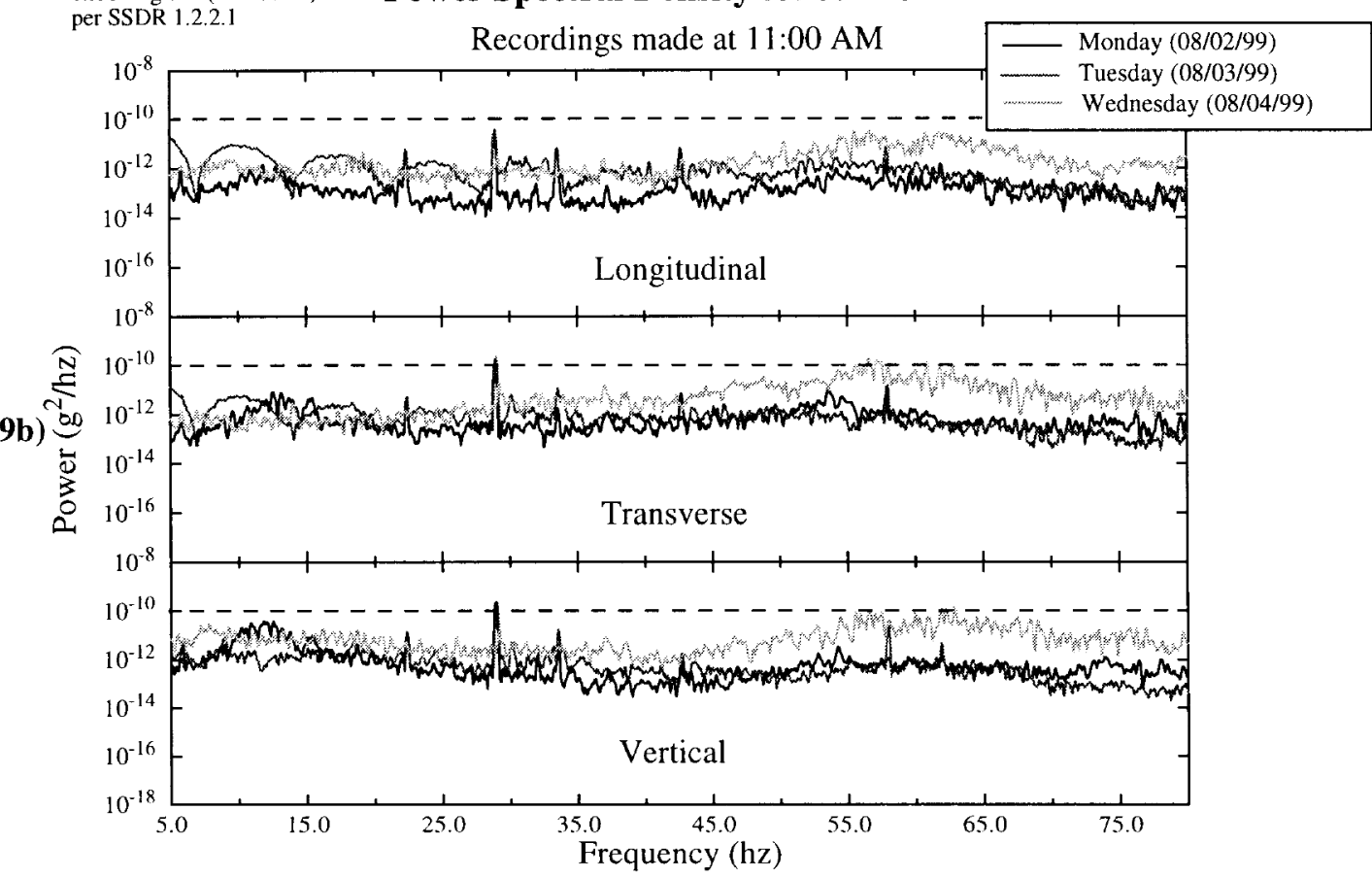


Conventional Facitlities

- Vibration Requirement

per SSDR 1.2.2.1

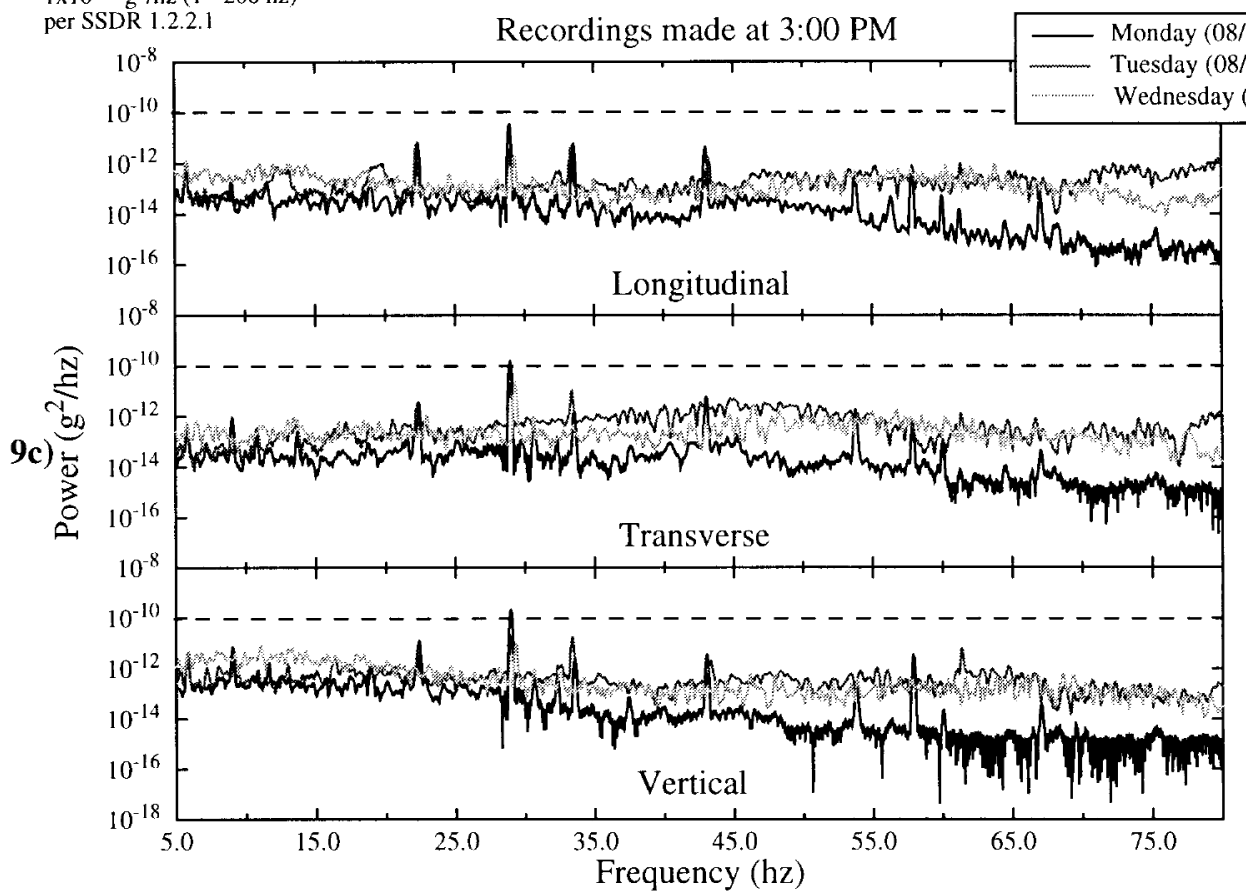

\section{Power Spectral Density for NIF OAB}

Recordings made at 3:00 PM - Monday (08/02/99)

(08) $(08 / 03 / 99)$

/04/99)

FIGURE 9. Power Spectral Density for NIF OAB. Recordings made at a) 9:00 AM, b) 11:00 AM, and c) 3:00 PM.

Conventional Facitlities

- - Vibration Requirement

$1 \times 10^{-10} \mathrm{~g}^{2} / \mathrm{hz}(1-200 \mathrm{hz})$

Power Spectral Density for NIF Central Plant

per SSDR 1.2.2.1

Recordings made at 3:00 PM (Isolated Slab)

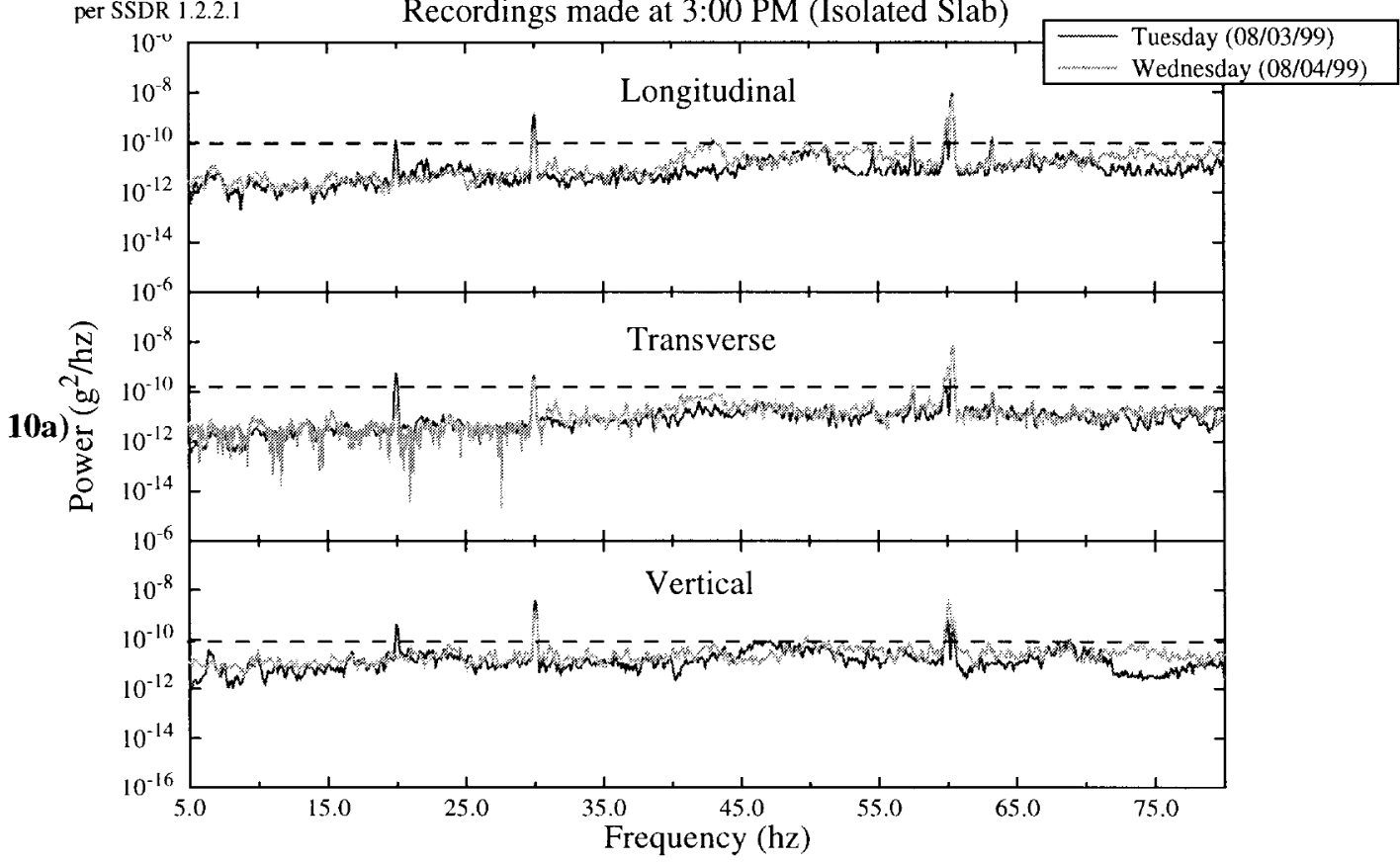


$1 \times 10^{-10} \mathrm{~g}^{2} \mathrm{hz}(1-200 \mathrm{hz}) \quad$ Power Spectral Density for NIF Central Plant

per SSDR 1.2.2.1 Recordings made at 3:00 PM (Main Slab)

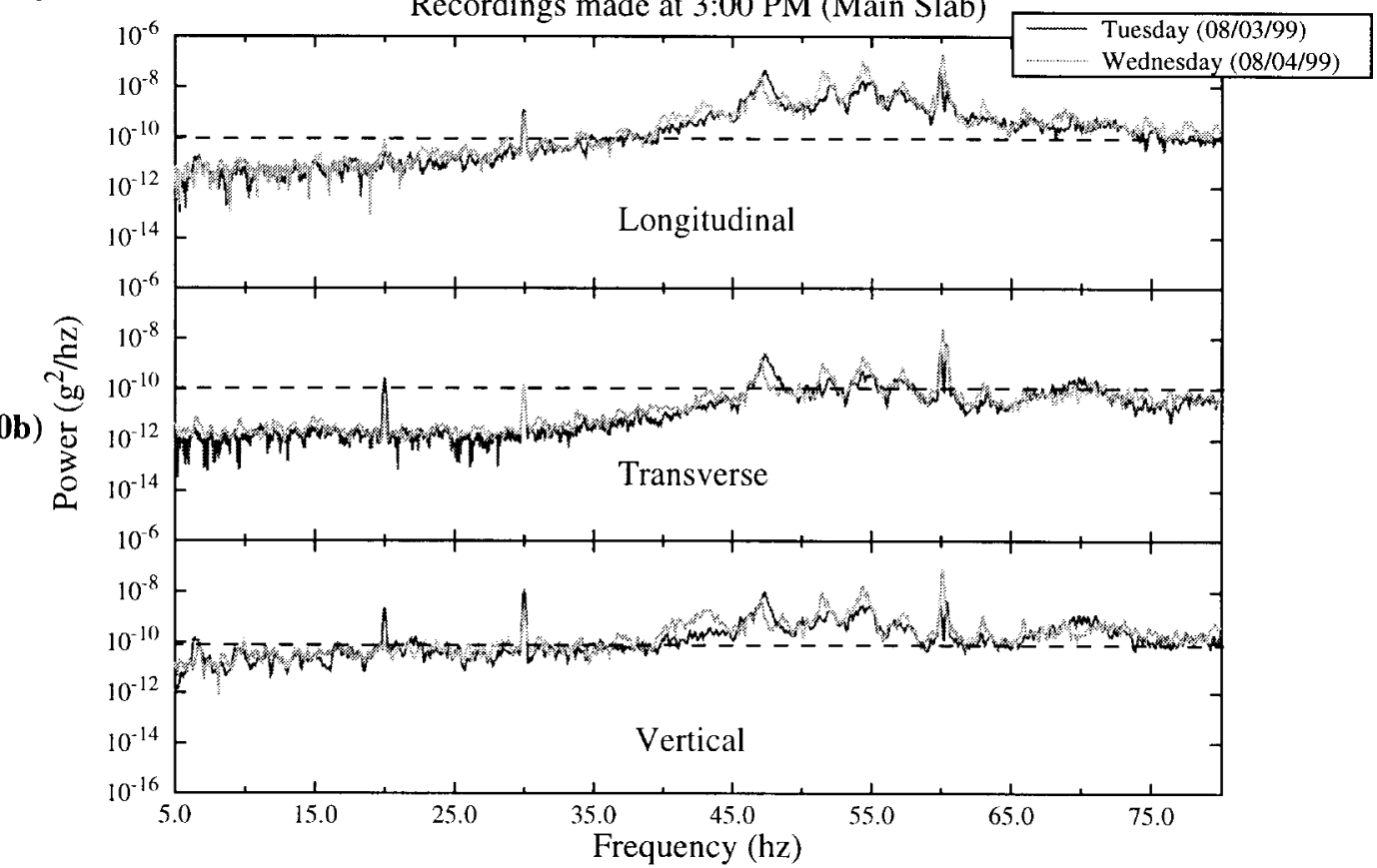

FIGURE 10. Power Spectral Density for NIF Central Plant. Recordings made at 3:00 PM for both a) the isolated slab and b) the main slab.

\section{PSD Comparison Between NIF OAB \& Central Plant}

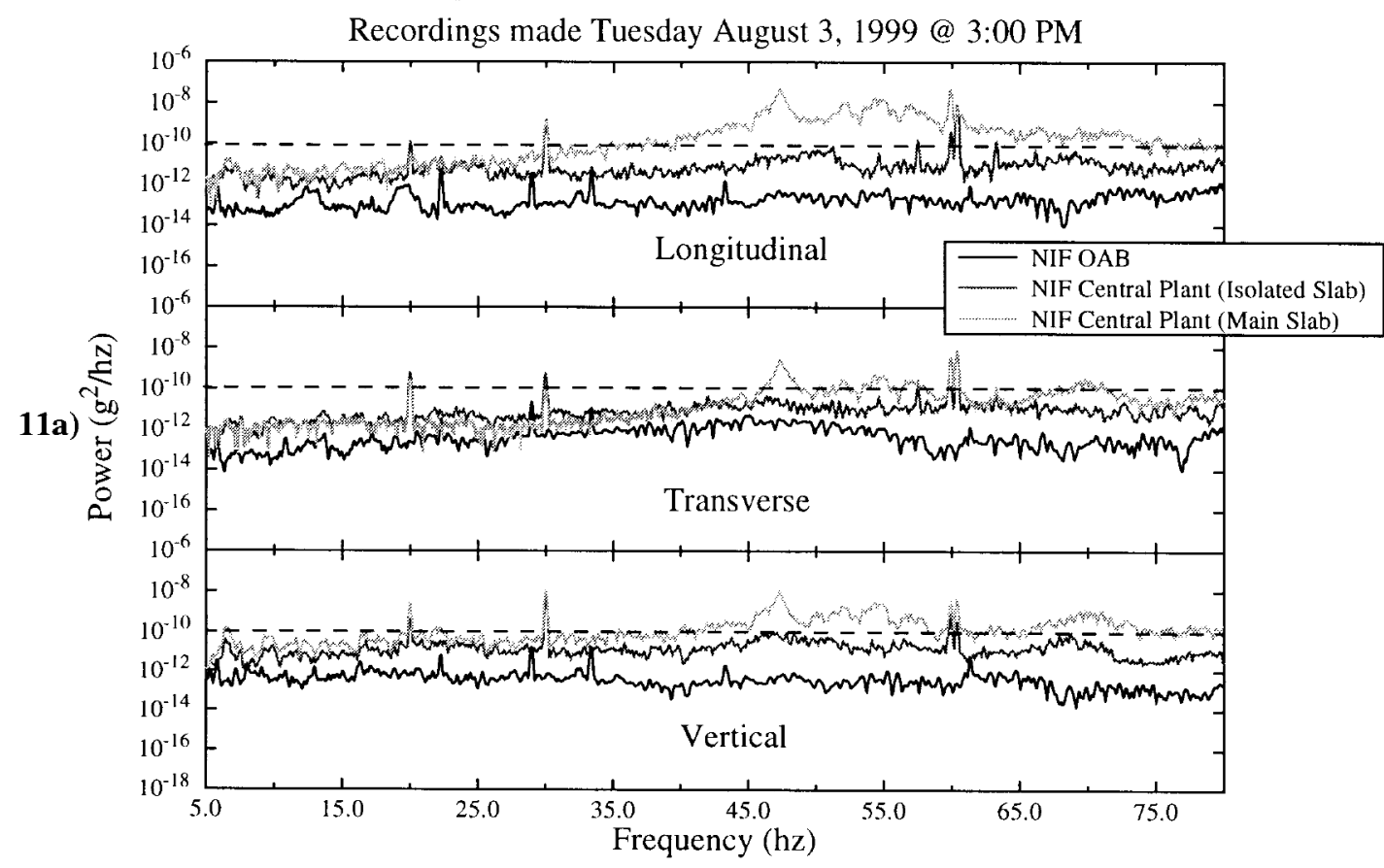




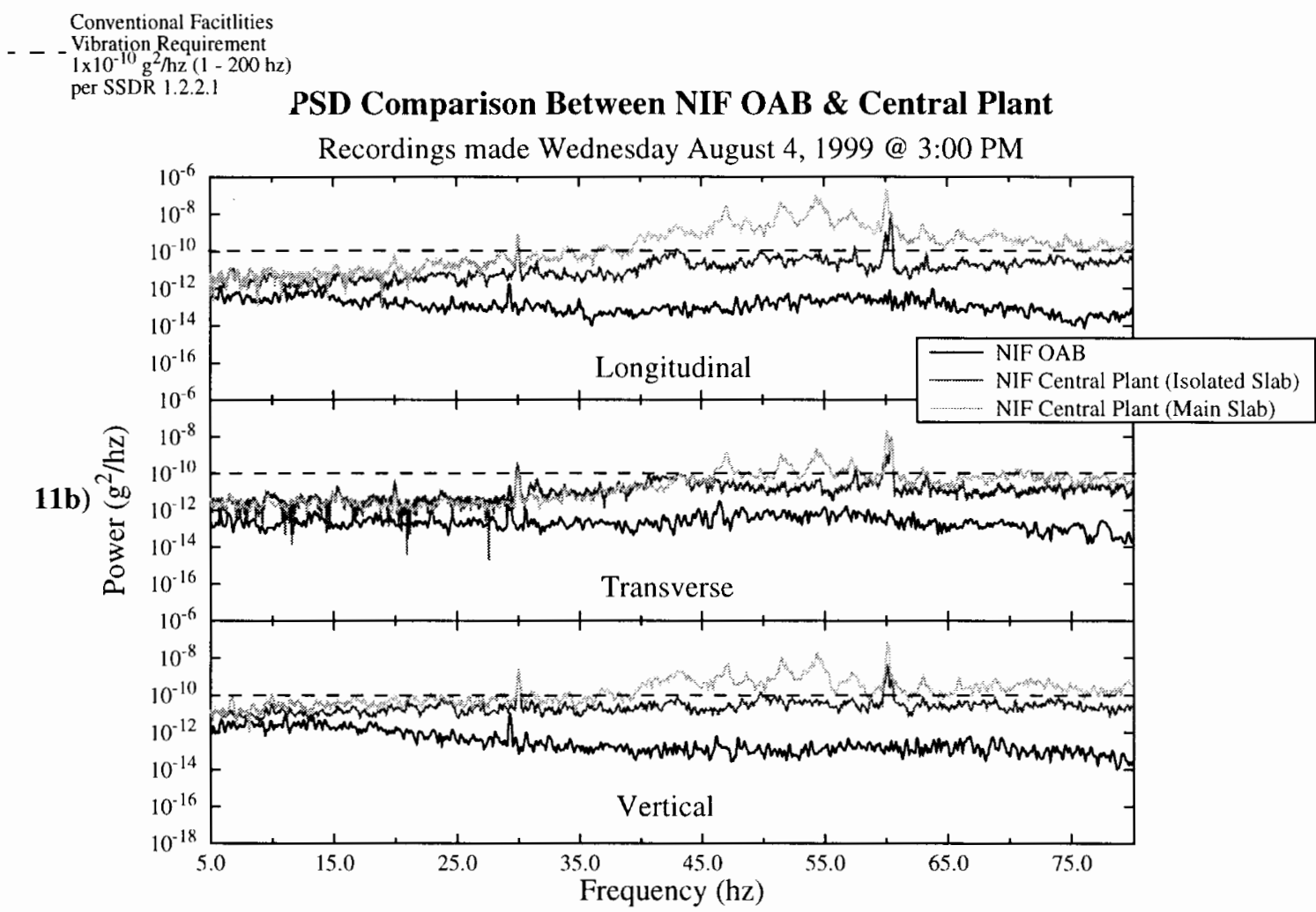

FIGURE 11. PSD comparison between NIF OAB \& Central Plant. Recordings made at 3:00 PM on a) Tuesday August 3 and b) Wednesday August 4.

Table 3: RMS Values For OAB (Terra DAS)

\begin{tabular}{|c|c|c|c|}
\hline Date & Time of Day & Direction & $\begin{array}{c}\text { RMS } \\
(\boldsymbol{\mu g ' s})\end{array}$ \\
\hline \hline Monday Aug. 2, 1999 & $9: 00 \mathrm{AM}$ & Longitudinal & $\mathbf{3 . 3 2}$ \\
\hline Monday Aug. 2, 1999 & $11: 00 \mathrm{AM}$ & Longitudinal & $\mathbf{4 . 7 7}$ \\
\hline Monday Aug. 2, 1999 & $3: 00 \mathrm{PM}$ & Longitudinal & $\mathbf{3 . 2 8}$ \\
\hline Monday Aug. 2, 1999 & $9: 00 \mathrm{AM}$ & Transverse & $\mathbf{6 . 1 7}$ \\
\hline Monday Aug. 2, 1999 & $11: 00 \mathrm{AM}$ & Transverse & $\mathbf{9 . 5 6}$ \\
\hline Monday Aug. 2, 1999 & $3: 00 \mathrm{PM}$ & Transverse & $\mathbf{5 . 5 8}$ \\
\hline Monday Aug. 2, 1999 & $9: 00 \mathrm{AM}$ & Vertical & $\mathbf{7 . 5 1}$ \\
\hline Monday Aug. 2, 1999 & $11: 00 \mathrm{AM}$ & Vertical & $\mathbf{1 2 . 8 4}$ \\
\hline Monday Aug. 2, 1999 & $3: 00 \mathrm{PM}$ & Vertical & $\mathbf{7 . 1 1}$ \\
\hline
\end{tabular}


Table 4: RMS Values For OAB (Terra DAS)

\begin{tabular}{|c|c|c|c|}
\hline Date & Time of Day & Direction & $\begin{array}{c}\text { RMS } \\
(\mu \mathbf{g} \text { 's }\end{array}$ \\
\hline \hline Tuesday Aug. 3, 1999 & $9: 00 \mathrm{AM}$ & Longitudinal & $\mathbf{1 4 . 2 5}$ \\
\hline Tuesday Aug. 3, 1999 & $11: 00 \mathrm{AM}$ & Longitudinal & $\mathbf{2 2 . 3 0}$ \\
\hline Tuesday Aug. 3, 1999 & $3: 00 \mathrm{PM}$ & Longitudinal & $\mathbf{4 3 . 0 7}$ \\
\hline Tuesday Aug. 3, 1999 & $9: 00 \mathrm{AM}$ & Transverse & $\mathbf{1 4 . 4 0}$ \\
\hline Tuesday Aug. 3, 1999 & $11: 00 \mathrm{AM}$ & Transverse & $\mathbf{1 8 . 7 3}$ \\
\hline Tuesday Aug. 3,1999 & $3: 00 \mathrm{PM}$ & Transverse & $\mathbf{7 . 4 2}$ \\
\hline Tuesday Aug. 3, 1999 & $9: 00 \mathrm{AM}$ & Vertical & $\mathbf{1 6 . 7 0}$ \\
\hline Tuesday Aug. 3, 1999 & $11: 00 \mathrm{AM}$ & Vertical & $\mathbf{1 1 . 3 9}$ \\
\hline Tuesday Aug. 3, 1999 & $3: 00 \mathrm{PM}$ & Vertical & $\mathbf{6 . 1 8}$ \\
\hline
\end{tabular}

Table 5: RMS Values For OAB (Terra DAS)

\begin{tabular}{|c|c|c|c|}
\hline Date & Time of Day & Direction & $\begin{array}{c}\text { RMS } \\
(\mu \mathbf{g})\end{array}$ \\
\hline \hline Wednesday Aug. 4, 1999 & $9: 00 \mathrm{AM}$ & Longitudinal & $\mathbf{5 . 0 0}$ \\
\hline Wednesday Aug. 4, 1999 & $11: 00 \mathrm{AM}$ & Longitudinal & $\mathbf{1 5 . 5 2}$ \\
\hline Wednesday Aug. 4, 1999 & $3: 00 \mathrm{PM}$ & Longitudinal & $\mathbf{3 . 9 1}$ \\
\hline Wednesday Aug. 4, 1999 & $9: 00 \mathrm{AM}$ & Transverse & $\mathbf{5 . 8 0}$ \\
\hline Wednesday Aug. 4, 1999 & $11: 00 \mathrm{AM}$ & Transverse & $\mathbf{2 8 . 5 9}$ \\
\hline Wednesday Aug. 4, 1999 & $3: 00 \mathrm{PM}$ & Transverse & $\mathbf{5 . 1 1}$ \\
\hline Wednesday Aug. 4, 1999 & $9: 00 \mathrm{AM}$ & Vertical & $\mathbf{9 . 6 8}$ \\
\hline Wednesday Aug. 4, 1999 & $11: 00 \mathrm{AM}$ & Vertical & $\mathbf{2 8 . 4 5}$ \\
\hline Wednesday Aug. 4, 1999 & $3: 00 \mathrm{PM}$ & Vertical & $\mathbf{7 . 5 6}$ \\
\hline
\end{tabular}


Table 6: RMS Values For Central Plant (RefTek DAS)

\begin{tabular}{|c|c|c|c|}
\hline Date & Time of Day & $\begin{array}{c}\text { Direction } \\
\text { (See Figs. } 1 \text { \& 2) }\end{array}$ & $\begin{array}{l}\text { RMS } \\
\left(\mu g^{\prime} s\right)\end{array}$ \\
\hline Tuesday Aug. 3, 1999 & 3:00 PM & 1 & 48.00 \\
\hline Tuesday Aug. 3, 1999 & 3:00 PM & 2 & 51.51 \\
\hline Tuesday Aug. 3, 1999 & 3:00 PM & 3 & 47.48 \\
\hline Tuesday Aug. 3, 1999 & 3:00 PM & 4 & 165.43 \\
\hline Tuesday Aug. 3, 1999 & 3:00 PM & 5 & 324.90 \\
\hline Tuesday Aug. 3, 1999 & 3:00 PM & 6 & 81.69 \\
\hline Wednesday Aug. 4, 1999 & 3:00 PM & 1 & 55.71 \\
\hline Wednesday Aug. 4, 1999 & 3:00 PM & 2 & 53.09 \\
\hline Wednesday Aug. 4, 1999 & 3:00 PM & 3 & $\mathbf{5 3 . 3 0}$ \\
\hline Wednesday Aug. 4, 1999 & 3:00 PM & 4 & 224.73 \\
\hline Wednesday Aug. 4, 1999 & 3:00 PM & 5 & 443.39 \\
\hline Wednesday Aug. 4, 1999 & 3:00 PM & 6 & 103.76 \\
\hline
\end{tabular}




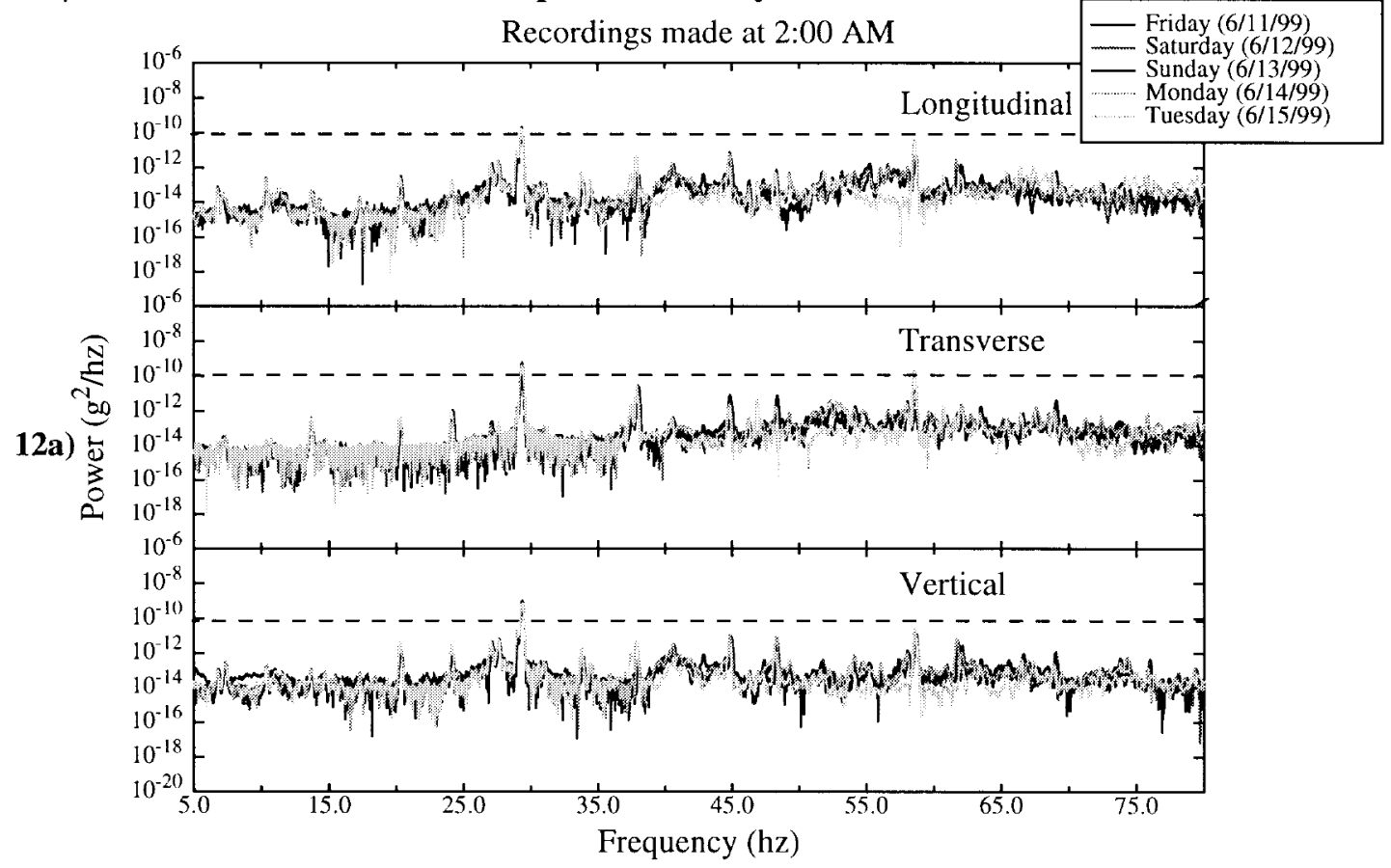

Conventional Facitlities

Power Spectral Density for NIF OAB

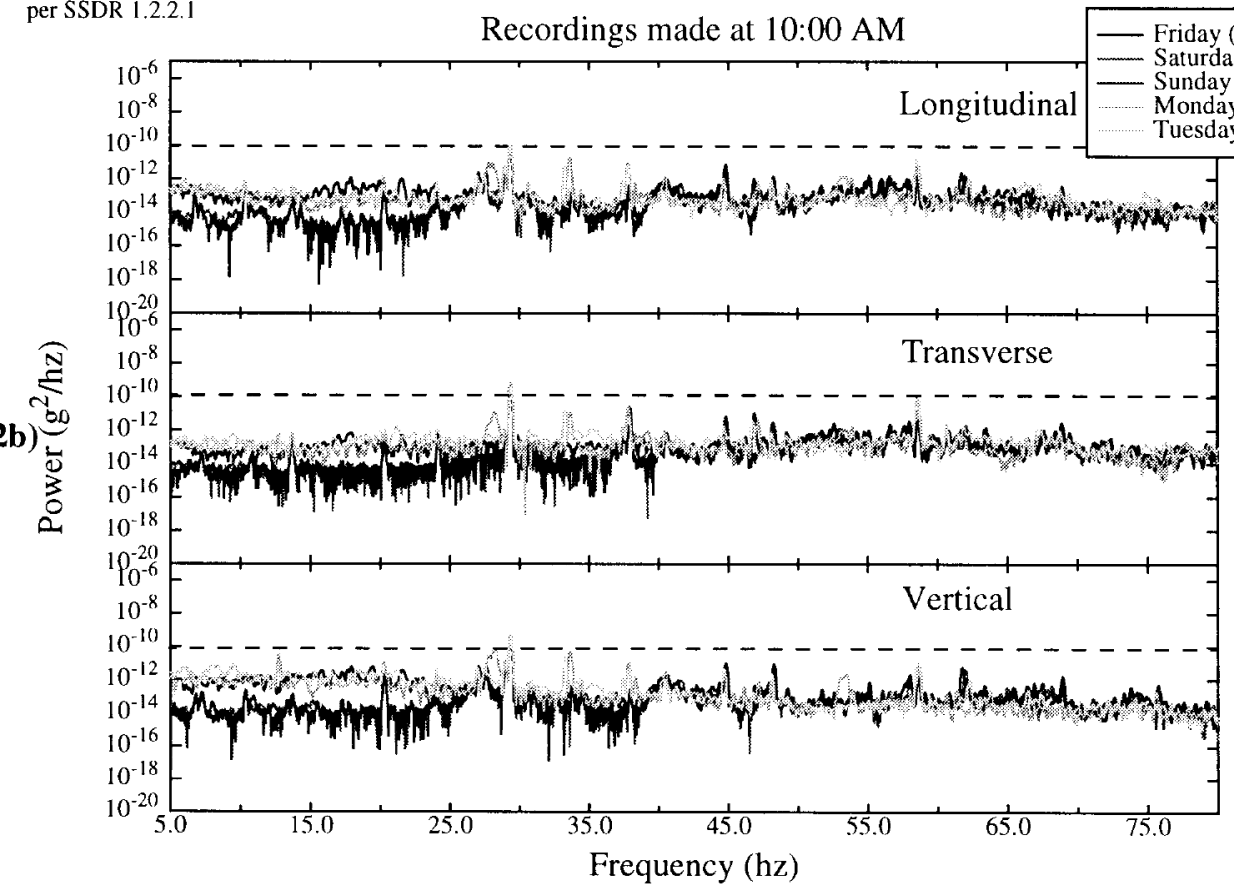


Conventional Facitlities

Vibration Requirement

$1 \times 10^{-10} \mathrm{~g}^{2} / \mathrm{hz}(1-200 \mathrm{hz})$

Power Spectral Density for NIF OAB

Recordings made at 4:00 PM

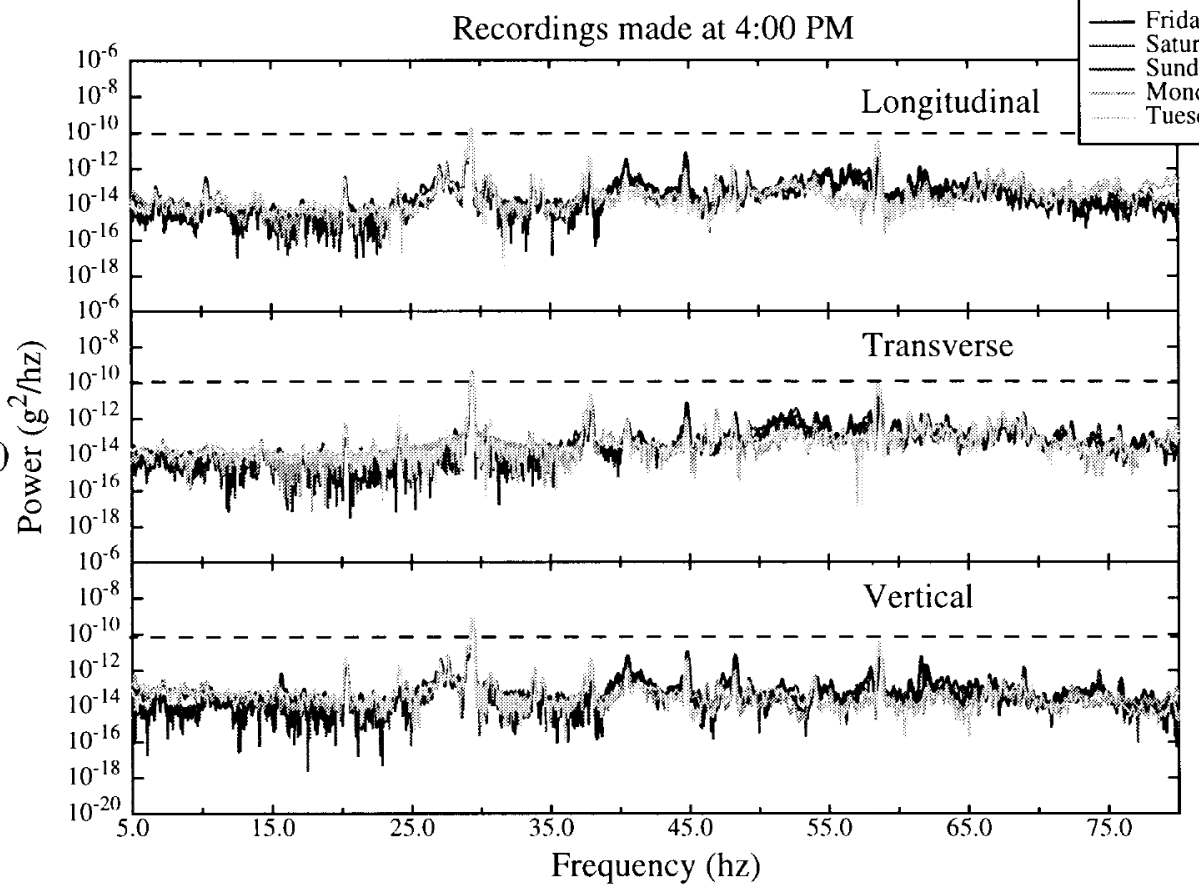

FIGURE 12. PSD for NIF OAB. Recordings made during the period of June 11-15, 1999 at a) 2:00 AM, b) 10:00 AM, and c) 4:00 PM.

Conventional Facitlities Vibration Requirement

- - - Vibration Requirement per SSDR 1.2.2.1

Power Spectral Density for NIF Central Plant

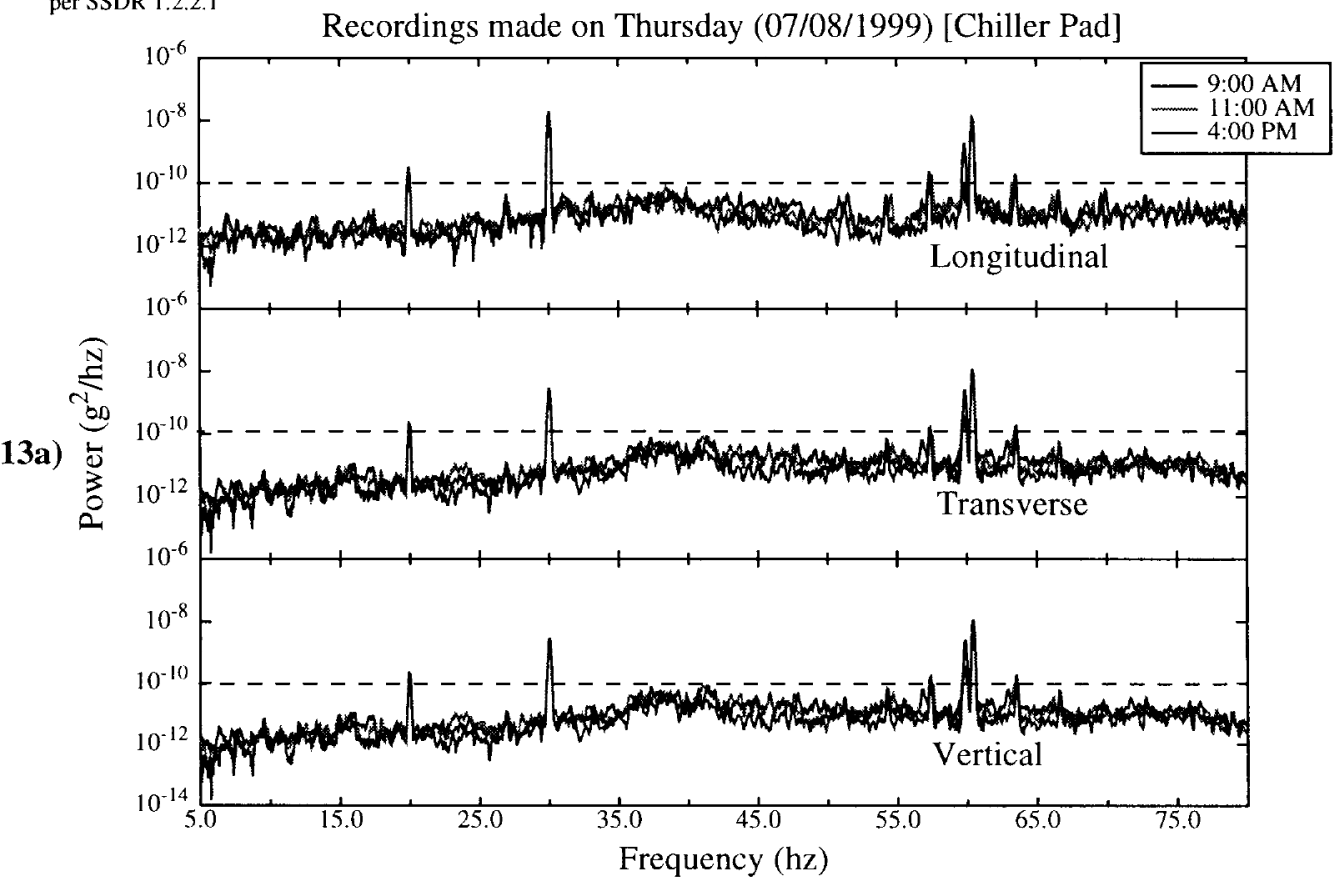


Conventional Facitlities

Vibration Requirement

$1 \times 10^{-10} \mathrm{~g}^{2} / \mathrm{hz}(1-200 \mathrm{hz})$

per SSDR 1.2.2.1

Power Spectral Density for NIF Central Plant

Recordings made on Thursday (07/08/1999) [Main Slab]

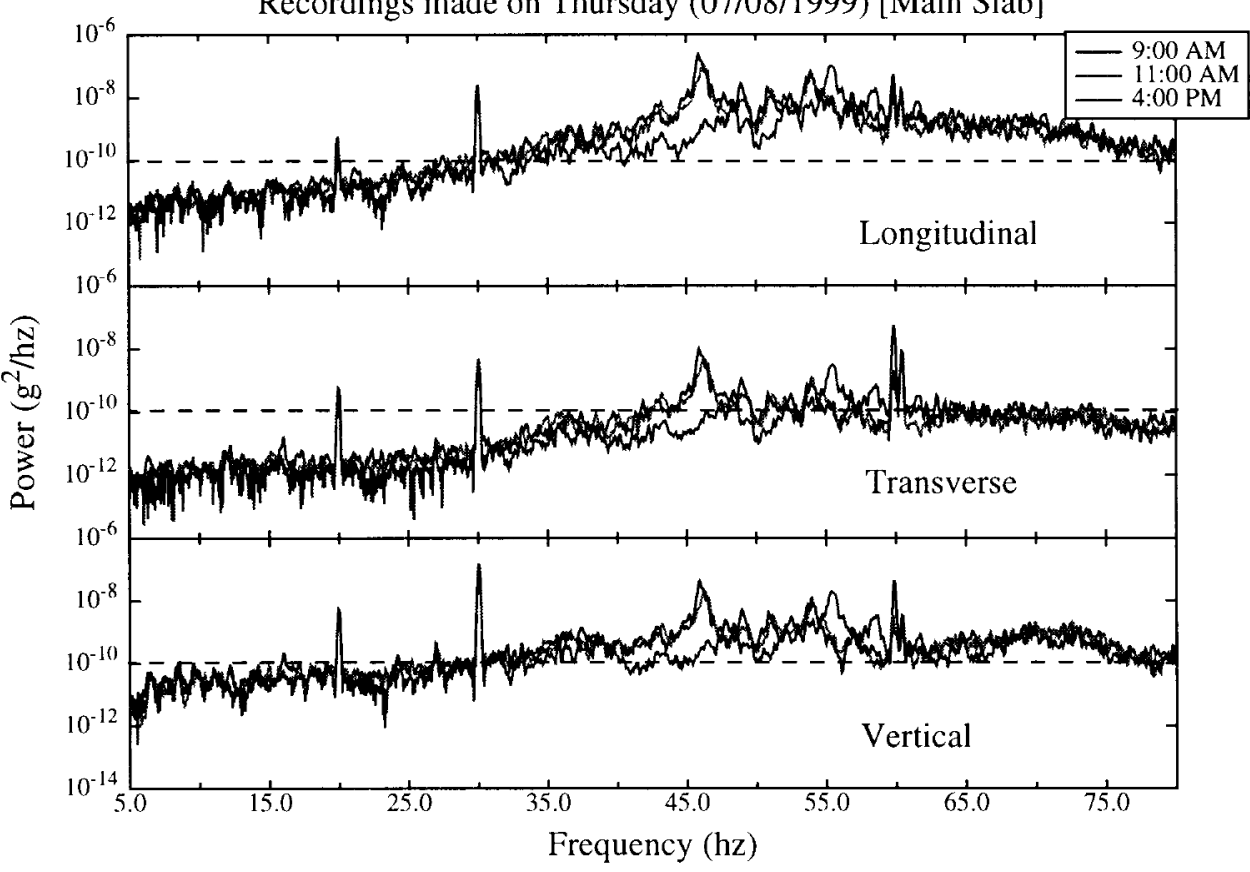

FIGURE 13. PSD for NIF Central Plant. Recordings made on Thursday July 8, 1999 for both a) the isolated slab and b) the main slab.

Conventional Facitlities

- Vibration Requirement

$1 \times 10^{-10} \mathrm{~g}^{2} / \mathrm{hz}(1-200 \mathrm{hz})$

per SSDR 1.2.2.1

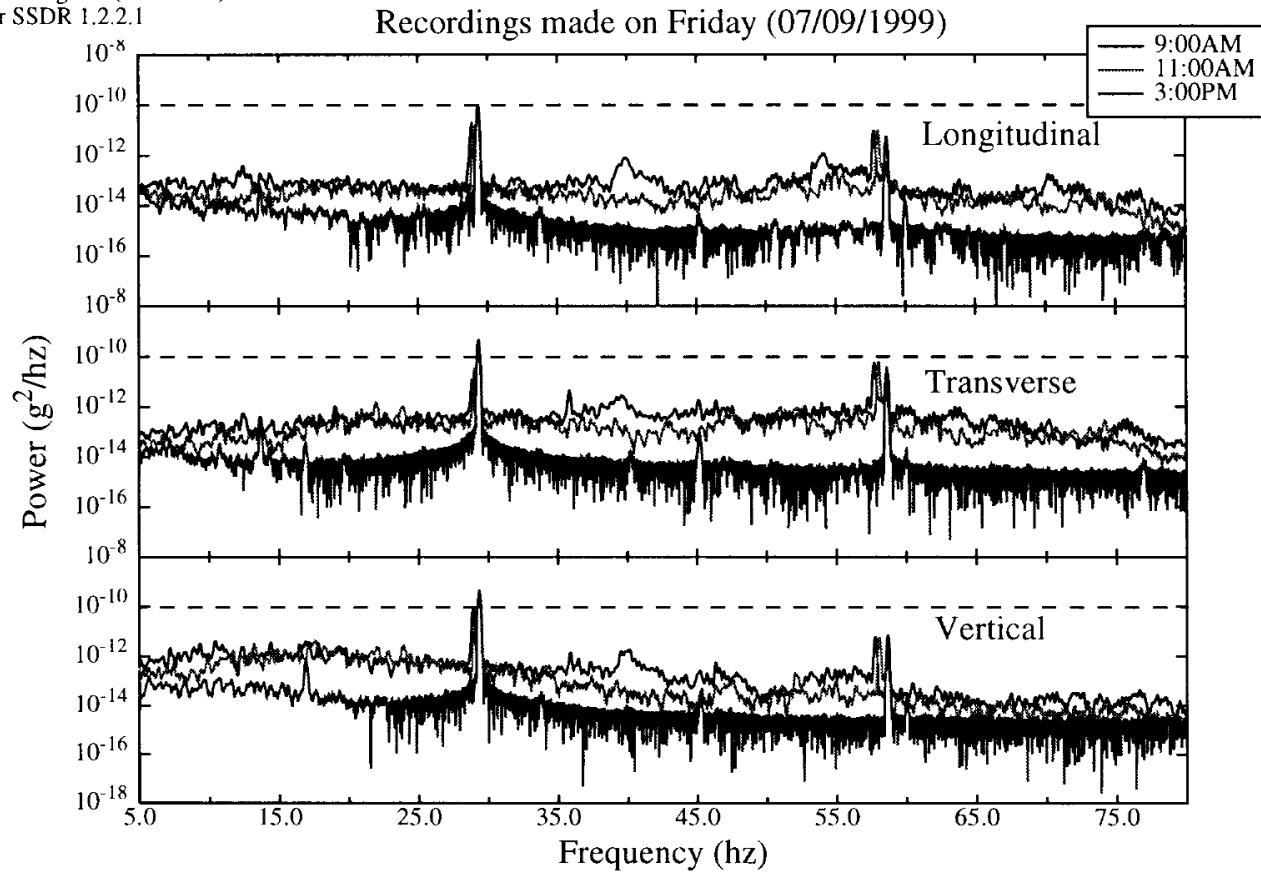

FIGURE 14. PSD for NIF OAB. Recording made on Friday July 9, 1999. 
Conventional Facitlities

Vibration Requirement

$1 \times 10^{-10} \mathrm{~g}^{2} / \mathrm{hz}(1-200 \mathrm{hz})$

per SSDR 1.2.2.1 Comparison of Power Spectral Density for NIF OAB

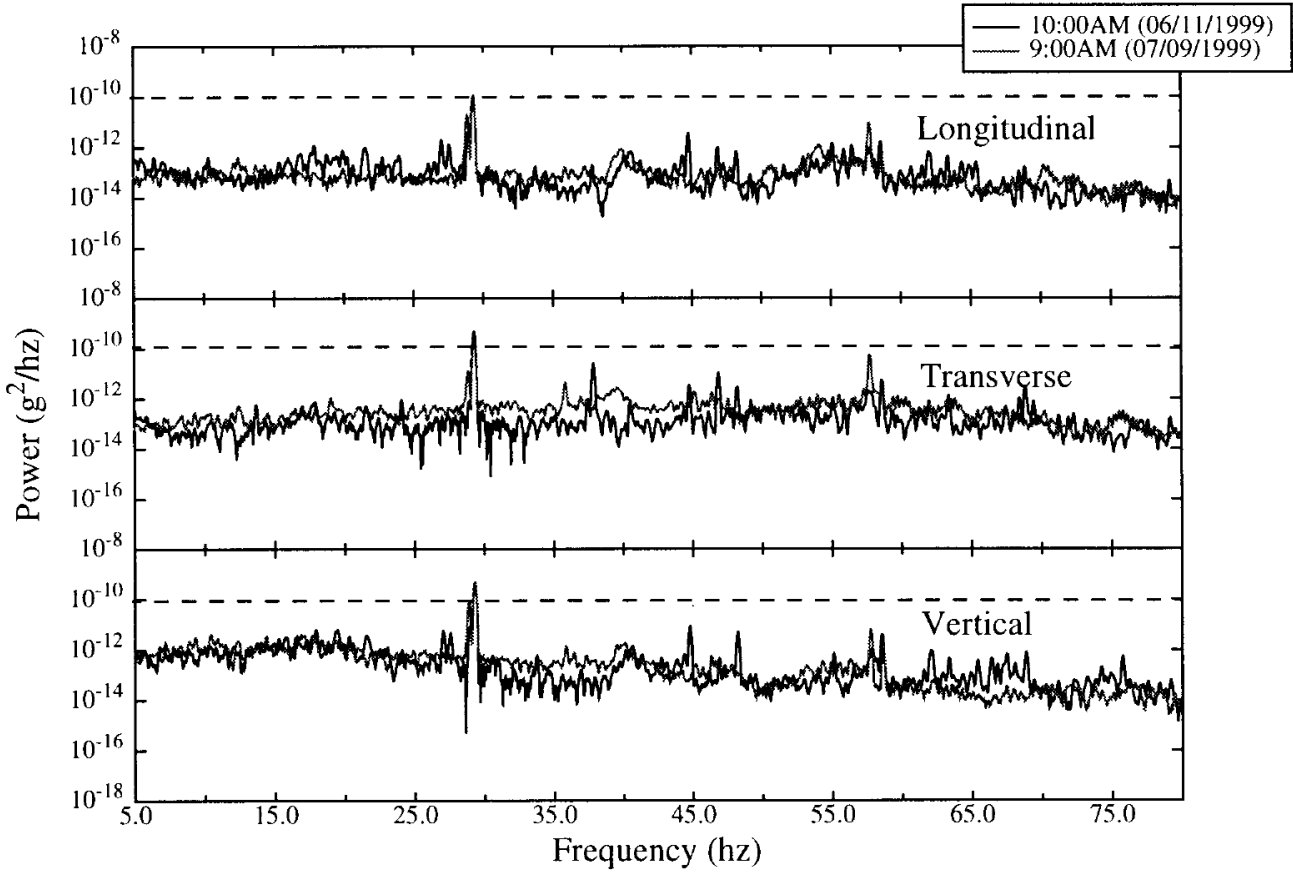

FIGURE 15. Comparison of PSD for NIF OAB. Data recorded at 10:00 AM on June 11, 1999 and at 9:00 AM on July 9, 1999.

Conventional Facitlities

Vibration Requirement

- - - $\begin{gathered}\text { Vibration } \\ 1 \times 10^{-10} \mathrm{~g}^{2} \mathrm{hz}(1-200 \mathrm{hz})\end{gathered}$ PSD Comparison for NIF OAB \& Central Plant per SSDR 1.2.2.

Recordings made at 9:00 AM on Friday (07/09/1999)

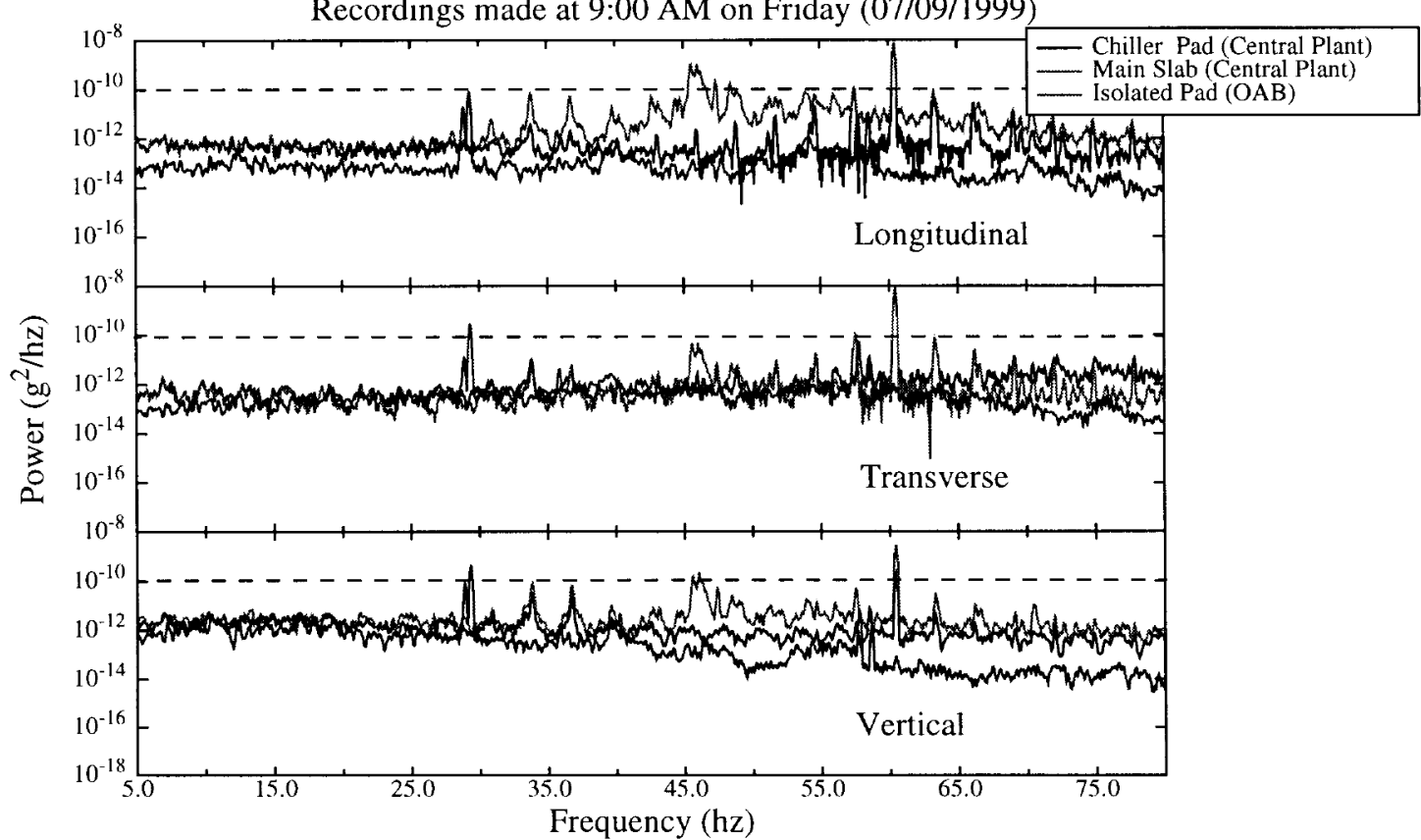

FIGURE 16. PSD comparison for NIF OAB \& Central Plant. Recordings were made at 9:00 AM on Friday July 9, 1999. 
Conventional Facitlities

Vibration Requiremen

$1 \times 10^{-10} \mathrm{~g}^{2} / \mathrm{hz}(1-200 \mathrm{hz})$

per SSDR 1.2.2.1

Power Spectral Density for NIF Central Plant

Recordings made on Thursday \& Friday [Chiller Pad]

17a)

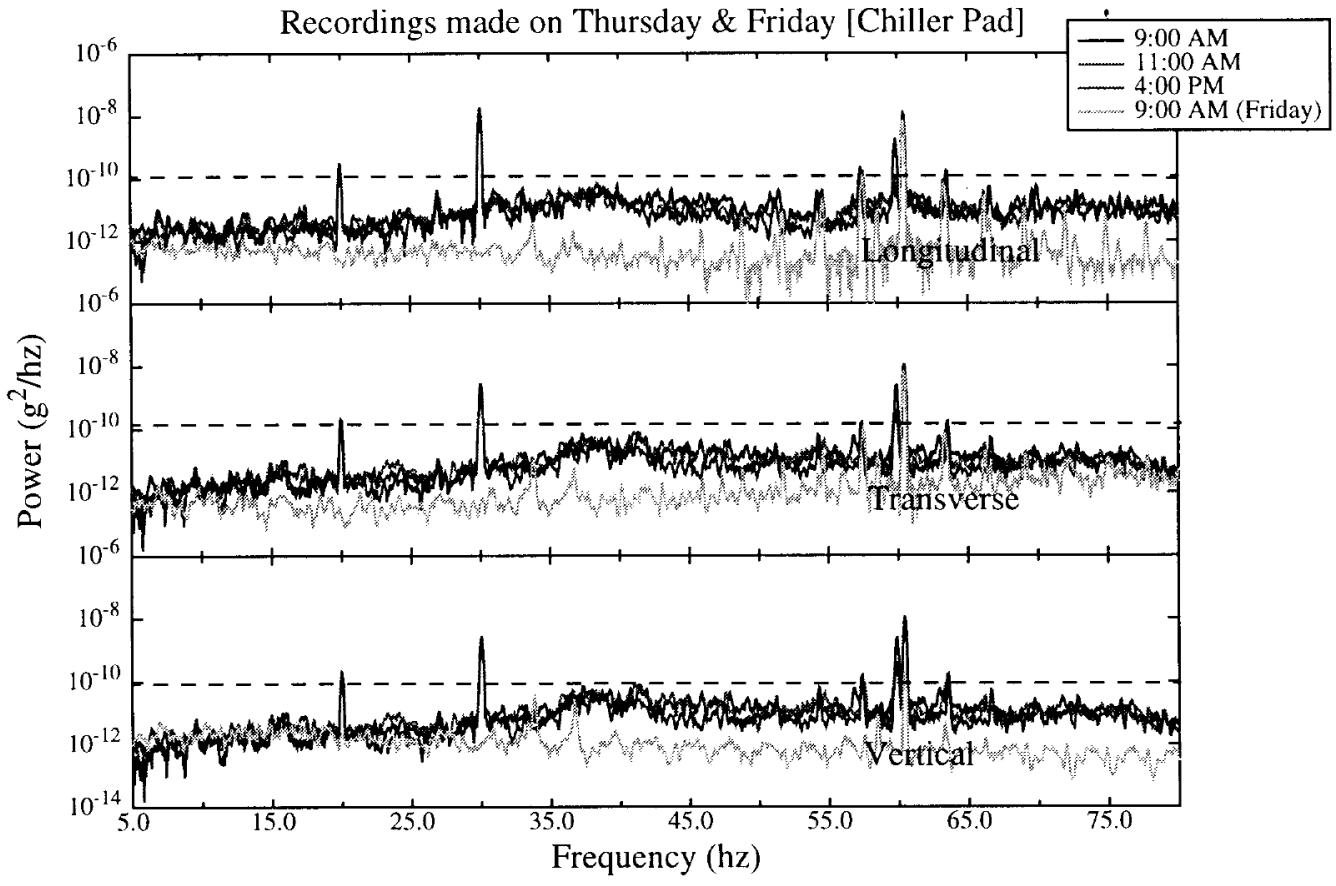

Conventional Facitlities

- - Vibration Requirement

$1 \times 10^{-10} \mathrm{~g}^{2} / \mathrm{hz}(1-200 \mathrm{hz})$

Power Spectral Density for NIF Central Plant

per SSDR 1.2.2.

Recordings made on Thursday \& Friday [Main Slab]

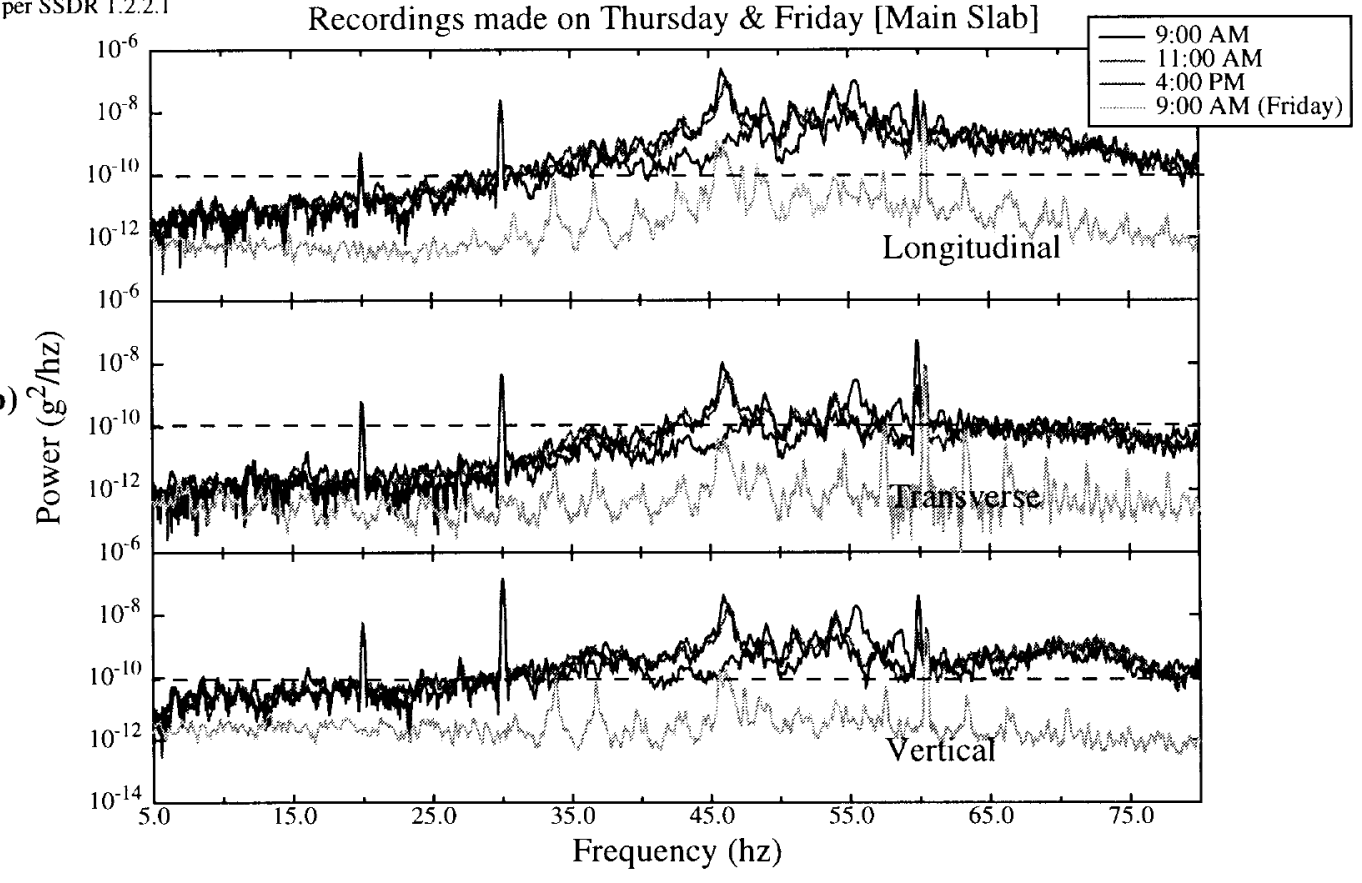

FIGURE 17. PSD for NIF Central Plant. Rcordings made on July 8 and July 9, 1999 for a) the generator pad and $b$ ) the main slab. 


\section{PSD Comparison for NIF OAB \& Central Plant}

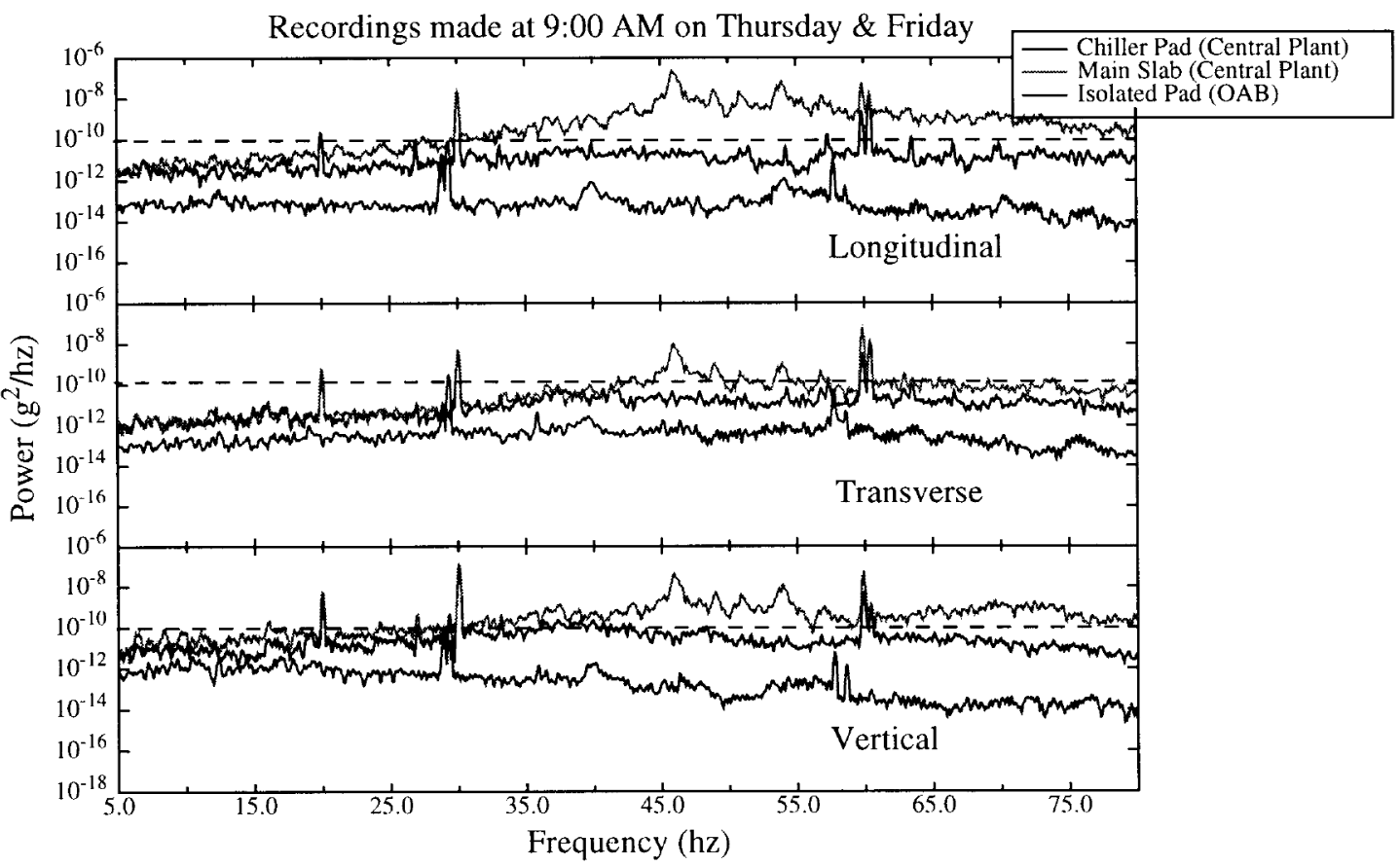

FIGURE 18. PSD comparison for NIF OAB \& Central Plant. Recordings made at 9:00 AM on Thursday July 8, 1999 and Friday July 9, 1999.

Table 7: RMS Values For OAB (Terra DAS)

\begin{tabular}{|c|c|c|c|}
\hline Date & Time of Day & Direction & $\begin{array}{c}\text { RMS } \\
(\boldsymbol{\mu g} \text { 's })\end{array}$ \\
\hline \hline Friday July 9, 1999 & $9: 00 \mathrm{AM}$ & Longitudinal & $\mathbf{5 . 1 5}$ \\
\hline Friday July 9, 1999 & $11: 00 \mathrm{AM}$ & Longitudinal & $\mathbf{4 . 9 6}$ \\
\hline Friday July 9, 1999 & $3: 00 \mathrm{PM}$ & Longitudinal & $\mathbf{4 . 2 0}$ \\
\hline Friday July 9, 1999 & $9: 00 \mathrm{AM}$ & Transverse & $\mathbf{9 . 6 2}$ \\
\hline Friday July 9,1999 & $11: 00 \mathrm{AM}$ & Transverse & $\mathbf{8 . 8 6}$ \\
\hline Friday July 9, 1999 & $3: 00 \mathrm{PM}$ & Transverse & $\mathbf{9 . 1 7}$ \\
\hline Friday July 9,1999 & $9: 00 \mathrm{AM}$ & Vertical & $\mathbf{1 1 . 1 0}$ \\
\hline Friday July 9, 1999 & $11: 00 \mathrm{AM}$ & Vertical & $\mathbf{1 0 . 8 0}$ \\
\hline Friday July 9,1999 & $3: 00 \mathrm{PM}$ & Vertical & $\mathbf{8 . 8 9}$ \\
\hline
\end{tabular}


Table 8: RMS Values For Central Plant Chiller Pad (RefTek DAS)

\begin{tabular}{|c|c|c|c|}
\hline Date & Time of Day & $\begin{array}{c}\text { Direction } \\
\text { (See Figs. 1 \& 2) }\end{array}$ & $\begin{array}{c}\text { RMS } \\
(\boldsymbol{\mu g} \text { 's })\end{array}$ \\
\hline \hline Thursday July 8, 1999 & $9: 00 \mathrm{AM}$ & 1 & $\mathbf{1 2 7 . 0 0}$ \\
\hline Thursday July 8, 1999 & $11: 00 \mathrm{AM}$ & 1 & $\mathbf{1 2 8 . 0 0}$ \\
\hline Thursday July 8, 1999 & $3: 00 \mathrm{PM}$ & 1 & $\mathbf{1 3 4 . 0 0}$ \\
\hline Thursday July 8, 1999 & $9: 00 \mathrm{AM}$ & 2 & $\mathbf{7 9 . 1 0}$ \\
\hline Thursday July 8,1999 & $11: 00 \mathrm{AM}$ & 2 & $\mathbf{8 0 . 0 0}$ \\
\hline Thursday July 8, 1999 & $3: 00 \mathrm{PM}$ & 2 & $\mathbf{8 1 . 1 0}$ \\
\hline Thursday July 8, 1999 & $9: 00 \mathrm{AM}$ & 3 & $\mathbf{6 3 . 5 0}$ \\
\hline Thursday July 8, 1999 & $11: 00 \mathrm{AM}$ & 3 & $\mathbf{5 3 . 2 0}$ \\
\hline Thursday July 8, 1999 & $3: 00 \mathrm{PM}$ & 3 & $\mathbf{5 5 . 1 0}$ \\
\hline
\end{tabular}

Table 9: RMS Values For Central Plant Main Slab (RefTek DAS)

\begin{tabular}{|c|c|c|c|}
\hline Date & Time of Day & $\begin{array}{c}\text { Direction } \\
\text { See Figs. 1 \& 2) }\end{array}$ & $\begin{array}{c}\text { RMS } \\
(\mu \mathrm{g} \text { 's }\end{array}$ \\
\hline \hline Thursday July 8, 1999 & $9: 00 \mathrm{AM}$ & 4 & $\mathbf{3 0 0 . 0 0}$ \\
\hline Thursday July 8, 1999 & $11: 00 \mathrm{AM}$ & 4 & $\mathbf{2 7 2 . 0 0}$ \\
\hline Thursday July 8, 1999 & $3: 00 \mathrm{PM}$ & 4 & $\mathbf{2 5 5 . 0 0}$ \\
\hline Thursday July 8, 1999 & $9: 00 \mathrm{AM}$ & 5 & $\mathbf{5 3 5 . 0 0}$ \\
\hline Thursday July 8, 1999 & $11: 00 \mathrm{AM}$ & 5 & $\mathbf{4 5 6 . 0 0}$ \\
\hline Thursday July 8, 1999 & $3: 00 \mathrm{PM}$ & 5 & $\mathbf{4 0 5 . 0 0}$ \\
\hline Thursday July 8, 1999 & $9: 00 \mathrm{AM}$ & 6 & $\mathbf{1 5 1 . 0 0}$ \\
\hline Thursday July 8, 1999 & $11: 00 \mathrm{AM}$ & 6 & $\mathbf{1 3 4 . 0 0}$ \\
\hline Thursday July 8, 1999 & $3: 00 \mathrm{PM}$ & 6 & $\mathbf{9 2 . 7 0}$ \\
\hline
\end{tabular}


Table 10: RMS Values For Central Plant Chiller Pad (RefTek DAS)

\begin{tabular}{|c|c|c|c|}
\hline Date & Time of Day & $\begin{array}{c}\text { Direction } \\
(\text { See Figs. 1 \& 2) }\end{array}$ & $\begin{array}{c}\text { RMS } \\
(\boldsymbol{\mu g} \mathbf{s})\end{array}$ \\
\hline \hline Friday July 9, 1999 & $9: 00 \mathrm{AM}$ & 1 & $\mathbf{1 2 . 3 0}$ \\
\hline Friday July 9, 1999 & $9: 00 \mathrm{AM}$ & 2 & $\mathbf{3 8 . 3 0}$ \\
\hline Friday July 9, 1999 & $9: 00 \mathrm{AM}$ & 3 & $\mathbf{3 7 . 9 0}$ \\
\hline
\end{tabular}

Table 11: RMS Values For Central Plant Main Slab (RefTek DAS)

\begin{tabular}{|c|c|c|c|}
\hline Date & Time of Day & $\begin{array}{c}\text { Direction } \\
\text { (See Figs. 1 \& 2) }\end{array}$ & $\begin{array}{c}\text { RMS } \\
(\boldsymbol{\mu g} \mathbf{s})\end{array}$ \\
\hline \hline Friday July 9, 1999 & $9: 00 \mathrm{AM}$ & 4 & $\mathbf{2 9 . 7 0}$ \\
\hline Friday July 9, 1999 & $9: 00 \mathrm{AM}$ & 5 & $\mathbf{5 0 . 5 0}$ \\
\hline Friday July 9, 1999 & $9: 00 \mathrm{AM}$ & 6 & $\mathbf{3 7 . 3 0}$ \\
\hline
\end{tabular}




\section{APPENDIX A}

\section{Explanation of Beating Phenomena}

Much of the recorded acceleration time history data measured at the NIF Optical Assembly Building $(\mathrm{OAB})$ experienced a phenomenon known as beats. Figure 1 shows an example of a record that exhibited this beating phenomena and figure 2 shows an example of a record that did not. Beats can occur when two harmonic motions with frequencies close to

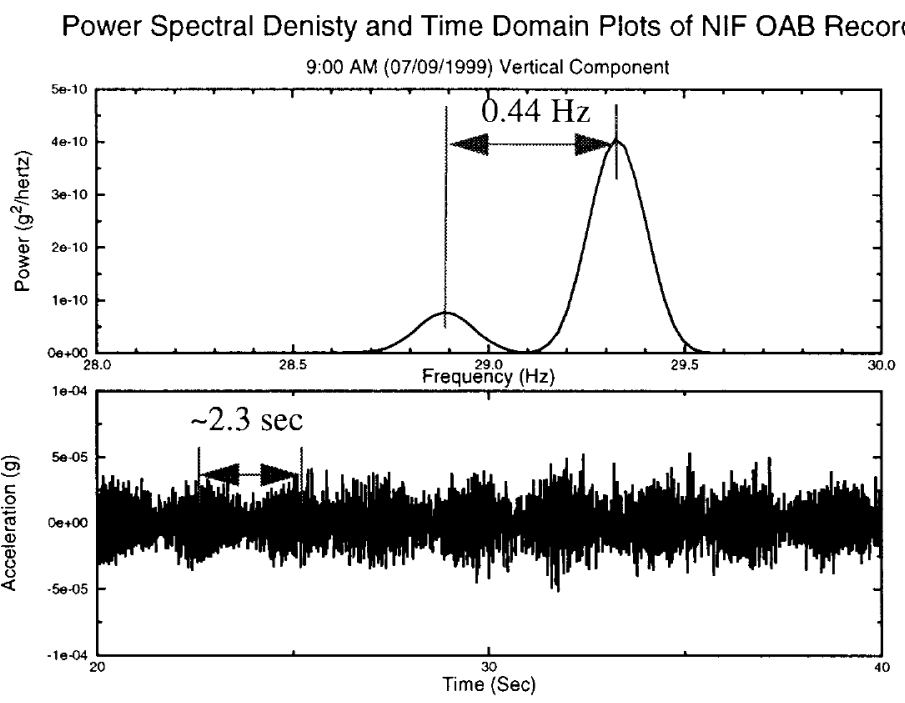

Figure 1. PSD and time history of a NIF OAB record experiencing beats.

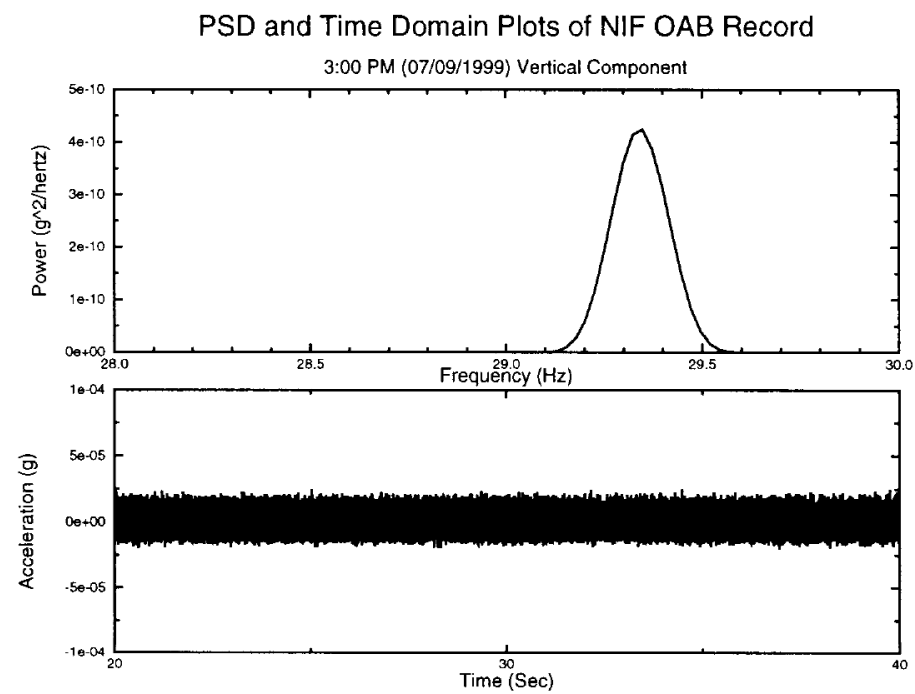

Figure 2. PSD and time history of a NIF OAB record not experiencing beats. 
one another are added. If

$$
\begin{gathered}
x_{1}(t)=X \sin \omega t \\
x_{2}(t)=X \sin (\omega t+\delta \omega t)
\end{gathered}
$$

where $\delta$ is a small quantity. The result of summing these two motions gives the following equation,

$$
x(t)=x_{1}(t)+x_{2}(t)=X[\sin \omega t+\sin (\omega t+\delta \omega t)] \quad \text { Eqn. } 1
$$

By using the trigonometric identity

$$
\sin A+\sin B=2 \sin \frac{A+B}{2} \cos \frac{A-B}{2}
$$

Equation 1 can be rewritten as

$$
x(t)=2 X \sin \left(\omega t+\frac{\delta \omega t}{2}\right) \cos \left(\frac{\delta \omega t}{2}\right) \quad \text { Eqn. } 2
$$

The resulting motion, $x(t)$, represents approximately a sine wave with frequency $\omega$ and amplitude building up and dying down with a frequency $\delta \omega$. This behavior is known as beats and the frequency with which the amplitude builds up and dies down, or $\delta \omega$, is known as beat frequency. For example, in Figure 1, the beat frequency can be clearly seen in the power spectral density as approximately $0.43 \mathrm{~Hz}$, which is a period of 2.33 seconds. This period of 2.33 seconds can be seen in the time history shown below the power spectral density. The period of 2.33 seconds, or $0.43 \mathrm{~Hz}$, is the amount of time it takes for the motion to die down and build up again. Notice in Figure 2 that the power spectral density is lacking this second frequency, thereby producing a time history that does not exhibit the beating phenomena. 


\section{APPENDIX B}

\section{Data Acquisition System and Sensor Package for Model Enhancement and Damage Detection Project}

\section{A Center for Complex Distributed Systems Technology Base Project}
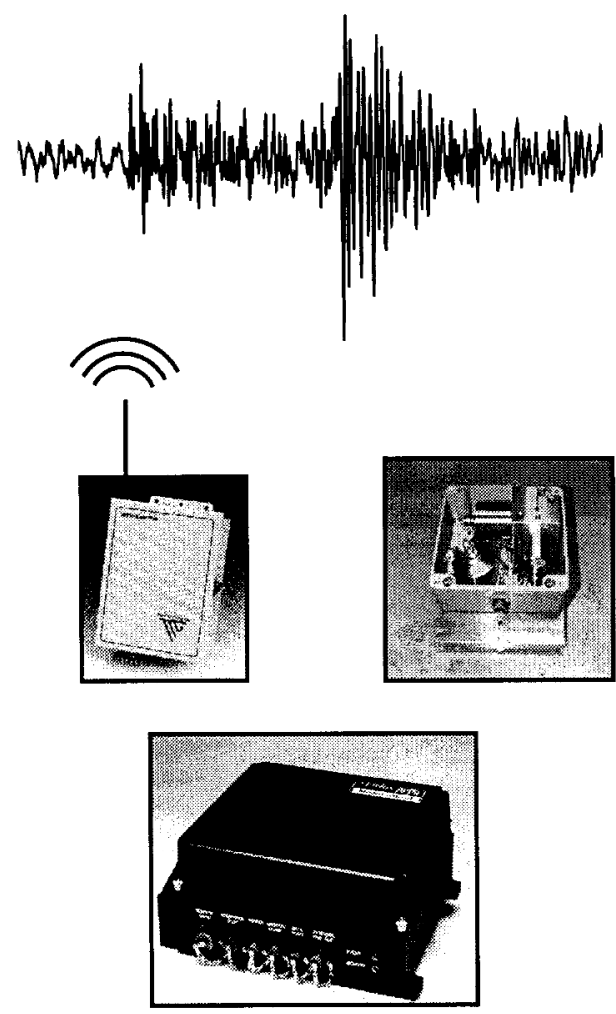

Matthew S. Hoehler

New Technologies Engineering Division Lawrence Livermore National Laboratory 


\title{
Data Acquisition System and Sensor Pack- age for Model Enhancement and Damage Detection Project
}

\author{
Matthew S. Hoehler ${ }^{\text {f }}$ \\ ${ }^{\$ 3}$ New Technologies Engineering Division \\ Lawrence Livermore National Laboratory
}

\subsection{Overview}

This report documents the implementation and testing of a data acquisition system (DAS) for vibration monitoring of large structures. The motivation for this work is a Technology Base (Tech Base) project to develop a fully integrated system to perform model enhancement and damage detection for large-scale structures. The Tech Base project is a multidisciplinary effort to develop both the mathematical and analytical toolboxes and the physical systems required to detect discrepancies between real structures and computer simulations.

The following report is divided into two sections. In Section 2.0 the data acquisition system is described and system capabilities and requirements are presented. Section 3.0 highlights some of the testing that was done to validate the system performance. In addition to providing documentation for work performed, this report is intended to serve as a reference for future users of these systems. 


\subsection{The Physical System}

\subsection{System Requirements}

The objectives of the Tech Base project and the nature of the structures that are being investigated place several unique requirements on the systems used for gathering structural behavior data. In particular, these systems must:

- allow for remote access for setting system parameters, triggering events, and downloading data

- capture a wide range of structural periods ranging from 10 seconds to 0.005 seconds

- measure a wide range of amplitudes ranging from ambient noise $(<\mu \mathrm{g})$ to strong motion $(2 \mathrm{~g})$

- be compact and rugged

- have the capability for extended autonomous functioning.

The above listed requirements moved us away from the traditional data acquisition system, which requires in-the-field data extraction, towards a system that allows remote system access. Several data acquisition system vendors offering remotely accessible systems were considered. Terra Technology Corporation based in Redman, Washington was selected as the company best suited to meet our needs. Terra has been making a concerted effort to continually update their products, particularly in the area of remote communications. Additionally, because they are a relatively small company, they were willing to work with us to modify their standard data acquisition package to meet our system requirements. 


\subsection{The Complete System}

The data acquisition systems are modular systems that can be separated into four distinct groups of components (See Figure 1). These components consist of the digital recorder,

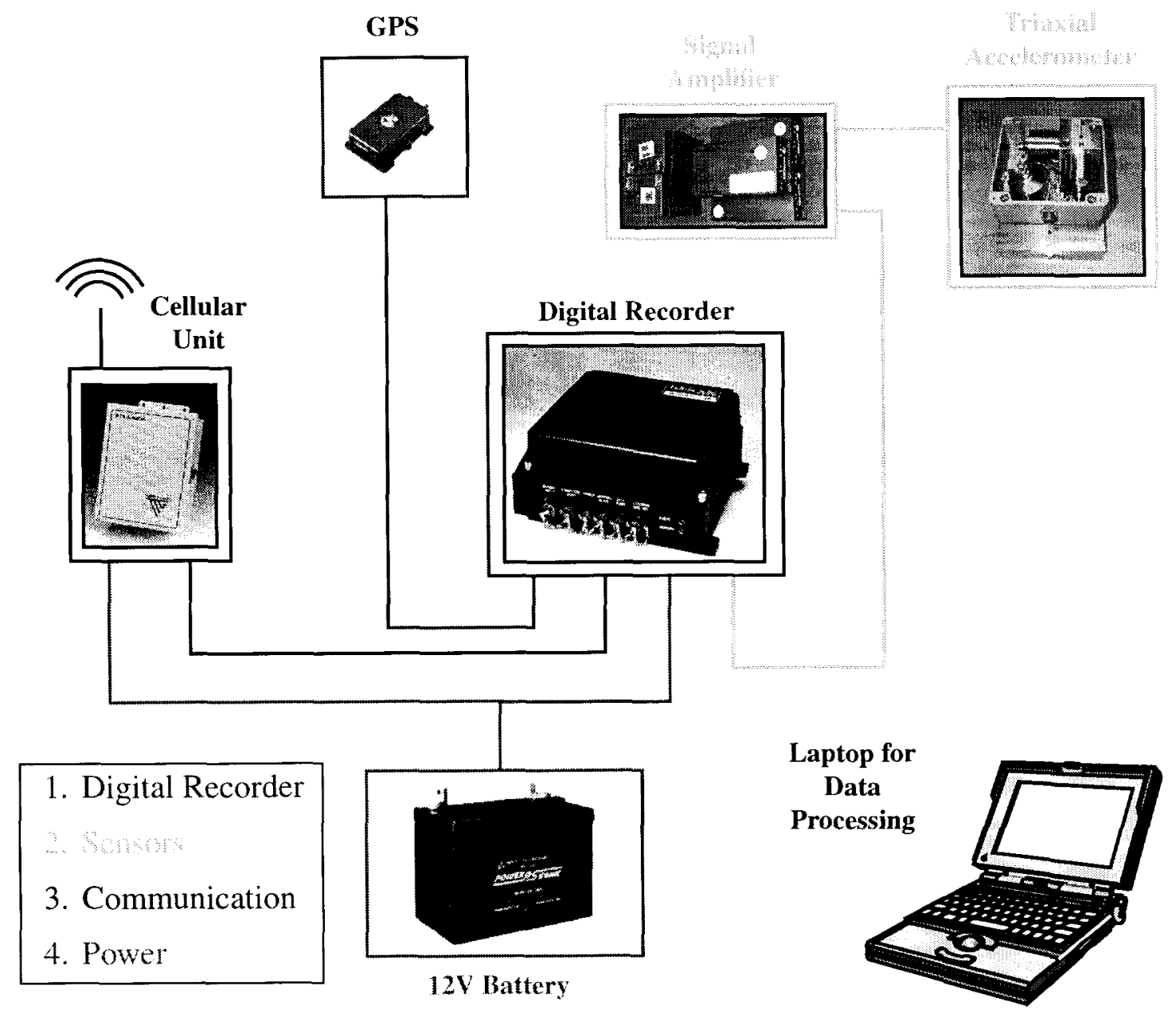

FIGURE 1. Schematic of data acquisition components

sensors, the communication unit, and a power supply. In the remainder of this section, each of these groups of components is discussed in detail. Wiring schematics showing explicit connections and connector types can be found in Appendix A: Connector Diagrams.

\subsection{Digital Recorder}

Several digital recorders were investigated for our project. Products from Jarpe Data Systems, Kinemetrics, and Terra Technology Inc. were considered during our final selection process. Terra Technology's GSR-18 digital recorder was selected because the standard system met most of our project requirements and Terra, being a small, dynamic company, was willing to work with us to meet the remainder of our requirements. 
The GSR-18 is a 22-bit analog to digital recorder. When sampling at 200 samples per second (sps) it provides 18-bit resolution of data. In addition to recording data, the GSR-18 has a GPS for timing, PCMCIA memory for data storage, power management circuitry, and a 33.8 modem for communication. In order to use the GSR-18 with our various sensor packages, it was necessary for Terra to install voltage correction circuitry to modify the standard 0 to +5 volt $(\mathrm{V})(+2.5 \mathrm{~V}$ offset) sensor input voltage to -5 to $+5 \mathrm{~V}(+0 \mathrm{~V}$ offset) input. The GSR-18 was also configured to accept external sensors and an external direct current (DC) power source.

The GSR-18 can be accessed directly (using a serial port) or remotely (using a modem and phone line) with a PC running Terra's Allview software. Allview provides a Graphical User Interface (GUI) for the GSR-18 allowing the operator to modify system parameters, trigger recordings, download data, and view and process data. The Allview software is constantly being updated and improved. New versions of the program can be obtained electronically from Louis Ho at Terra Technology.

\section{User Tips:}

Use of the GSR-18 is documented, although somewhat poorly, in the GSR-18 manual and accompanying Allview manual. The following user tips do not attempt to duplicate the operation instructions provided in these manuals, but rather provide insights obtained from using the system.

\section{Allview}

1. Allview works more reliably when executed from a true DOS platform. I will often process and view downloaded data by simply opening a DOS prompt from Windows 98 , however, when I actually connect to the GSR-18 I will reboot the computer and go directly to DOS.

2. Turn off "DC drift compensation" located in "Analog Signals (Numerical)" in the "Recorder Display" menu if you want to record frequencies below $1 \mathrm{~Hz}$.

3. Do not use the "Analog Signals (Graphical)" option in the "Recorder Display" menu. The processor in the GSR-18 is not fast enough to make this feature of any use and the strain on the system can cause the GSR-18 to crash.

4. Restarting the module using the "Restart Module" command can often clear problems with the recorder.

5. Alt+"the red letter" (not simply "the red letter") is the shortcut for the four main menu selections in Allview (i.e Help, Recorder, Inst-Config, PC-Files).

\section{Modem}

6. We are paying for the cellular phone using a commercial cellular provider. Airtime is expensive ( 25 cents per minute). DO NOT USE THE "READ ALL" COMMAND. Selectively download events and LOGOUT IMMEDIATELY AFTER DOWNLOAD.

7. Be patient. The modem connection is quite slow. 
8. Frequent disconnects caused by poor cellular coverage can be mitigated by increasing the "modem time out" length in the "PC Comm Port Setup" menu. The factory default setting is 20 ticks. The current setting is 500 ticks ( 27 seconds).

9. Cellular signal is stronger before 8:00AM.

10.Allview won't run with a PCMCIA modem. DOS usually does not operate a Win Modem. Therefore, the best modem for use with Allview is a simple external modem.

11.Use 1200 baud for all modem connections \& 19200 or 38400 for serial port connections.

12. When changing the baud rate in the "Communication" setting, the modem must be unchecked for the changes to take effect.

\section{Memory}

13.There appears to be data loss/corruption problems when the Viking PCMCIA memory cards are removed from the GSR-18.

14.If the PCMCIA memory gets unexpectedly full and you cannot access "Event Recording Files", use the "Delete Events" menu option to purge events from the PCMCIA card.

\section{Processing}

15.The current process for post-processing of data is to 1) download the files from the GSR-18 2) convert the .GSR files to SUDS format files using the "Convert to SUDS" (32 bit) command in the "PC-Files" menu 3 ) ftp the files to a UNIX workstation (binary transfer) 4) Read the files using the "readsuds" command in SAC2000. I am currently working on a script called "convertSUDS.csh" that will help automate processing of data using SAC2000. This script can be executed on a Sun workstation running SAC2000.

\subsection{Sensors}

Selecting a sensor capable of meeting our project needs proved to be one of the more challenging aspects of this project. The ideal sensor for this project would have the following qualities; the sensor would:

- measure accelerations from the sub-micro gravity range all the way up to $2 \mathrm{~g}$ 's

- accurately measure frequencies ranging from 0.05 to $200 \mathrm{~Hz}$

- come in a small, lightweight, easy to mount enclosure

- be low cost

The problem encountered when trying to meet all of these requirements is that in order to measure very low amplitude vibrations, one has to give up strong motion measuring capabilities. And conversely, a sensor capable of capturing strong motion ( $2 \mathrm{~g}$ 's) is usually quite noisy. Furthermore, while many companies claim to have sensors capable of measur- 
ing down to $\mathrm{DC}$, field tests often prove that it can be difficult to observe frequencies below $1 \mathrm{~Hz}$.

Two different sets of sensors have been selected for use with our data acquisition systems. The first is the Wilcoxon Research 731A piezoelectric accelerometer. The 731 A is an extremely delicate accelerometer, laboratory tested to measure from 0.05 to $450 \mathrm{~Hz}$ for accelerations up to $0.5 \mathrm{~g}$ 's. This sensor was chosen primarily for measuring ambient vibrations at the National Ignition Facility (NIF). The problem with this sensor is its inability to capture strong motion and its significant cost. For the systems that will be deployed on the San Francisco-Oakland Bay Bridge, Terra Technology SSA-SLN series sensors were purchased. These sensors can measure up to $2 \mathrm{~g}$ 's and product literature states that they will adequately measure small amplitude motions below $1 \mathrm{~Hz}$.

\subsubsection{Wilcoxon 731A Accelerometers and P31 Amplifiers}

The Wilcoxon 731A piezoelectric accelerometer is a $10 \mathrm{~V} / \mathrm{g}$ sensor commonly used for high-sensitivity modal testing. The P31 amplifier that accompanies the 731A accelerometer gives the operator the option of gaining the $10 \mathrm{~V} / \mathrm{g}$ signal by 1,10 or 100 times. Because modal testing usually requires only a short-term deployment of instruments ( 1 or 2 days), it was necessary to modify the systems for long-term field deployment. In particular, we developed a weather-proof triaxial enclosure for the accelerometers and modified the amplifiers to accept an alternative power source to extend runtime.

The 731A triaxial enclosures were engineered to minimize damping effects and provide direct coupling of the sensor to a structure. A photograph of the completed enclosure is shown below (See Figure 2). The cylindrical accelerometers are affixed directly to a 0.75

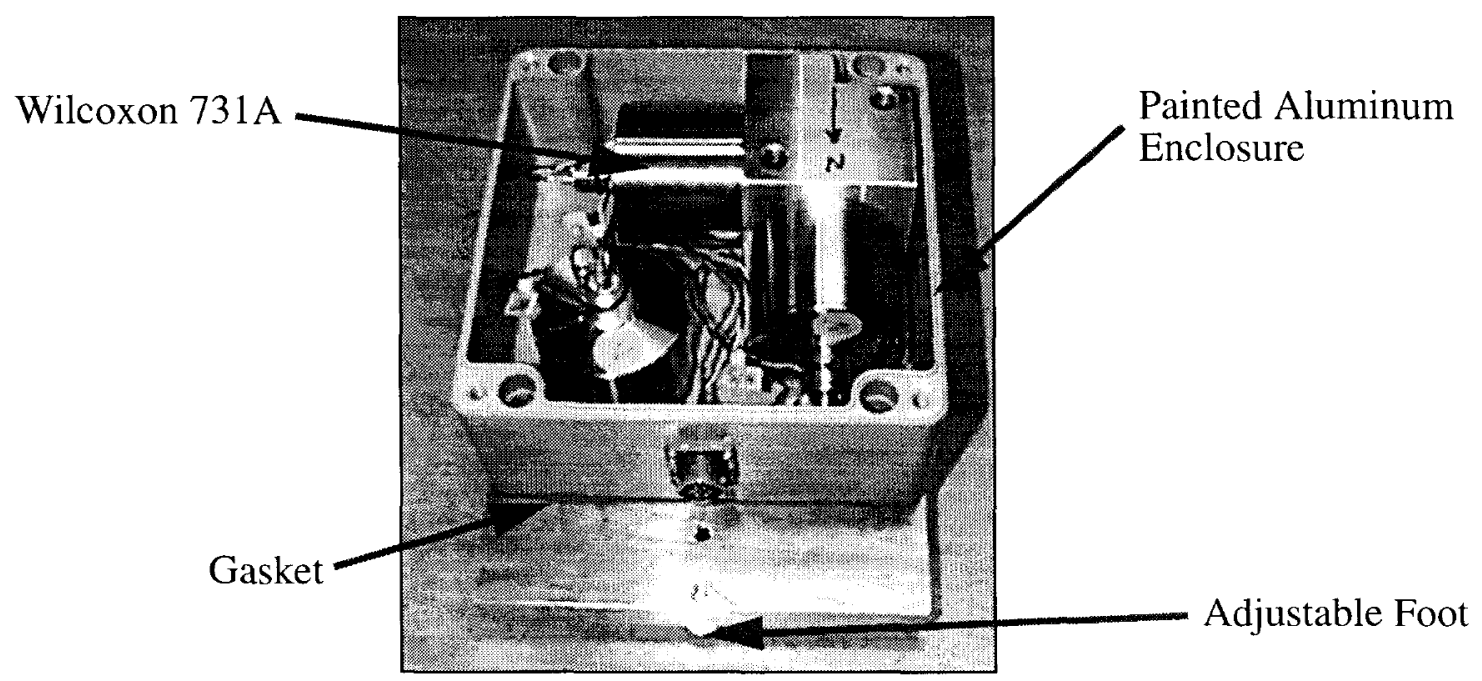

FIGURE 2. Triaxial enclosure for Wilcoxon 731A accelerometers

inch thick aluminum plate through cutouts in the weather-proof box. The painted aluminum box is affixed to the plate and sealed with a rubber gasket. The plate contacts the structure via three adjustable feet. Detailed designs for the enclosures can be found in Appendix B: Plans for Wilcoxon 731A Triaxial Enclosure. 
The P31 amplifiers are normally powered by four $9 \mathrm{~V}$ batteries that provide approximately 150 hours ( $\sim 6$ days) of operation. To extend the runtime the amplifiers were modified to accept $+-12 \mathrm{~V}$ provided by two 7 Amp hour (Ah) batteries. These batteries extend the runtime to approximately 623 hours ( $\sim 26$ days). The change in the voltage supply necessitated the replacement of the $\mathrm{C} 7$ capacitor with a high quality resin dipped capacitor (See Appendix C: Wiring Diagram for Wilcoxon P31 Amplifier). The reader should note that the wiring diagram does not appear to necessitate this modification, however, testing proved the necessity of the change.

\subsubsection{Terra Technology SSA-SLN Series Accelerometers}

At the writing of this report the SSA-SNL accelerometers have not yet been purchased. Product literature states that the sensors will record from DC to $50 \mathrm{~Hz}$ and allow us to record both strong and weak motion vibrations.

\subsection{Communication}

The field of data acquisition has been revolutionized in recent years with the advent of new communication technologies. The traditional monitoring system requiring in-the-field extraction of data is being replaced by systems capable of remote transmission of data via cellular or other communication. Our goal of performing damage detection, and restricted access to many of the structures that we are interested in monitoring, necessitated a data acquisition system with the capability for remote access.

Cellular communication was selected for use with our early systems. Cellular has the advantages of being relatively inexpensive for a small number of systems and it makes use of the wide coverage by commercial cellular providers. The two major drawbacks to using cellular are 1) phones require significant power, even in stand-by mode and 2) data transfer can be extremely slow.

The power problem was solved by selecting a cellular communication device that incorporated both a cellular phone for data transmission and a digital pager that functions as a low-power, remote off/on switch. The RTS-AutoPac, manufactured by TransTel Group Inc., combines a 3-watt Motorola phone, digital pager, and power management circuitry. The pager can be left on all the time with very little draw on the batteries. To activate the cellular system the user must first call the pager number and enter a page code and they can then dial into the GSR-18 to extract data. The phone automatically powers down five minutes after the connection is terminated. The units have the additional feature of automatically generating a dial tone so that the cellular phone mimics a land-line and can be used with the GSR-18 without modifications.

The problem of slow data transfer is more complicated and has not yet been resolved. Currently, we have achieved a maximum of 1200 baud transfer rate using the cellular connection. There are cellular phone/modem combinations that have achieved much higher data transfer rates. 
User Tips:

TABLE 1. List of current phone and pager numbers

\begin{tabular}{|c|c|c|}
\hline Phone S/N & Phone \# (GTE wireless) & Pager \# (PageMart) \\
\hline \hline DF69104F & (925) 989-5476 & \\
\hline D440568A & $(925)$ 989-5477 & \\
\hline & & \\
\hline & & \\
\hline
\end{tabular}

1. Page code for activation of phones: $\mathbf{1 1 1 1}$

2. Allow 30 seconds to 2 minutes between paging the system and attempting to access the system via modem.

3. The phone can be programmed in "test mode" using any cellular handset. The phone should be returned to "normal" mode for data acquisition. Phone numbers were programed by Wayne Turek of the radio shop and phone and pager numbers were assigned by Tina Jensen (See Contacts).

4. By plugging a cellular handset into the RJ-45 data jack and placing the phone in "test mode" the user can view the signal strength by observing the last three digits that appear on the handset. The digits can range from 0 to 150 . A signal strength of 80 is a minimum signal strength required for data transfer; 100 is preferable.

5. The remote paging switch can be by-passed by removing the power management circuit board and replacing it with an 8-pin shunt. This has the effect of turning the phone permanently on, which can be useful in locations with cellular, but no paging coverage.

\subsection{Power}

Power for the system is provided by an external 12 volt DC power supply. Typically, a large (40 - 100 Amp hour (Ah)), gel cell, slow discharge type battery is used.

The system can function off of this battery for a finite length of time, or it can run indefinitely if the battery is used in conjunction with a charging source (e.g. a solar panel or alternating current (AC) charger). It should be noted that the use of an external charger (AC in particular) can potentially induce current fluctuations that will affect the recorded data. This phenomenon was not observed in any of the system tests, however, a detailed study was not performed. If extended runtimes are required, power fluctuations can be minimized with the use of a suitable, quick charging solar cell.

Total system runtime, in the absence of an external charging source, is determined by the size of the battery and the current draw of the system components. Table 2 shows the draw of various system components. This table can be used to determine the runtime for various system configurations. 
TABLE 2. Current draw for system components

\begin{tabular}{|c|c|c|}
\hline Component & Status & $\begin{array}{c}\text { Current Draw } \\
(\mathbf{m A})\end{array}$ \\
\hline \hline GSR-18 & Stand-by & 300 \\
\hline GPS & Receive & 100 \\
\hline RTS-AutoPac & Receive & 120 \\
\hline RTS-AutoPac & Receive \& Transmit & 590 \\
\hline RTS-AutoPac (Pager) & Standby & 10 \\
\hline Wilcoxon P31 (per Ch.) & On & $6^{\mathrm{a}}$ \\
\hline SSA-120SLN & On & $30^{\mathrm{b}}$ \\
\hline SSA-220SLN & On & $50^{\mathrm{b}}$ \\
\hline SSA-320SLN & On & $70^{\mathrm{b}}$ \\
\hline
\end{tabular}

a. Wilcoxon $\mathrm{P} 31$ amplifiers use an independent $12 \mathrm{DC}$ power source and are not part of the main system battery load.

b. Current draws are from factory specifications.

The following example shows the computation of expected autonomous runtime for a GSR-18 system using the RTS-AutoPac with the pager feature and a SSA-320SLN sensor package. This would be a typical configuration for the San Francisco-Oakland Bay Bridge sites. Runtime is based on the stand-by current draw because this will be the draw on the system the majority of the time. A peak draw calculation is also shown for the system when all components are active (e.g. during data download). The peak draw value can be used to determine an appropriate solar cell size.

\section{EXAMPLE}

Components: GSR-18, GPS, RTS-AutoPac (w/ pager), SSA-320SLN, 40 Ah battery

Stand-by

GSR-18: $\quad 300 \mathrm{~mA}$

RTS-AutoPac (pager): $10 \mathrm{~mA}$

SSA-320SLN: $\quad 70 \mathrm{~mA}$

$380 \mathrm{~mA}$

$80 \%$ of $40 \mathrm{Ah}=32 \mathrm{Ah}$ (runtime discounted to reflect variability in batteries)

$32 \mathrm{Ah} / 0.380 \mathrm{~A}=84$ hours

Peak

GSR-18: $\quad 300 \mathrm{~mA}$

GPS: $\quad 100 \mathrm{~mA}$

RST-AutoPac (Rx/Tx): $590 \mathrm{~mA}$

RTS-AutoPac (pager): $10 \mathrm{~mA}$

SSA-320SLN: $\quad 70 \mathrm{~mA}$

$1070 \mathrm{~mA}$ 


\subsection{Testing}

To verify that the completed system was performing as expected, a series of controlled records were made using one signal source and multiple recording devices. This type of test is commonly referred to as a "huddle test" (See Figure 3). These tests were in addition to tests performed at the factory for calibration and system performance verification.

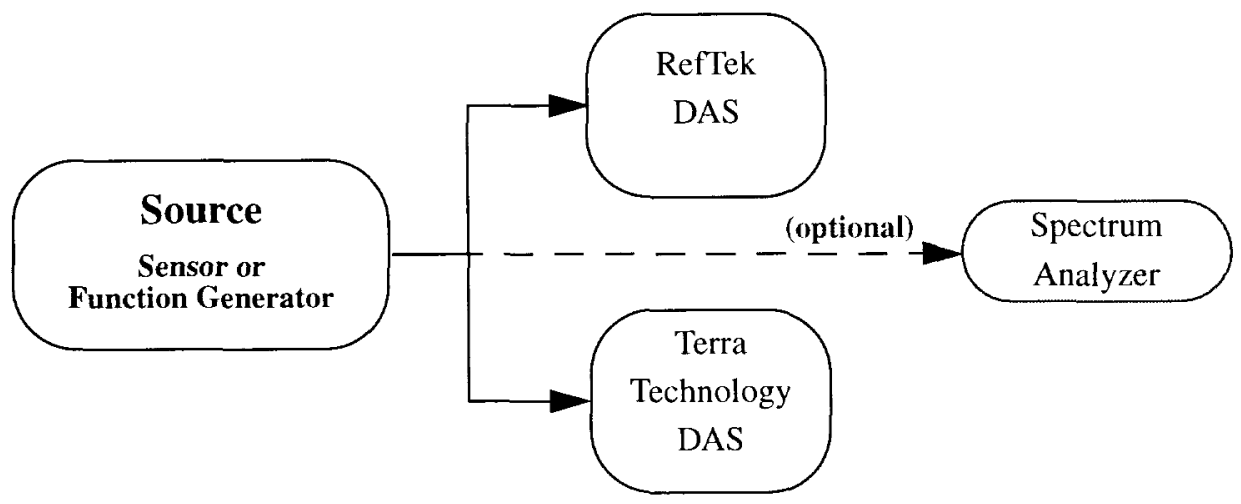

FIGURE 3. Diagram of huddle test

Three types of signals were recorded:

1. swept sine waves generated by a function generator.

2. background noise sensed using a Wilcoxon 731 A accelerometer.

3. background noise with intermittent foot stomps sensed using a Wilcoxon $731 \mathrm{~A}$ accelerometer.

The input signals were recorded simultaneously on a Refraction Technology digitizer, which has been used for years by the Earth Sciences Division at LLNL for seismic monitoring, and on the GSR-18. Additionally, the signal was monitored in real-time in the frequency domain using a Hewlett Packard spectrum analyzer.

Tests verified that the analog to digital (A/D) conversion was correct and that the amplitude and the frequency content of the two records did not vary significantly between the recording systems (See Figure 4 through Figure 6). Figure 4 and Figure 5 show the amplitude portion of a Fast Fourier Transform (FFT) and the Power Spectral Density (PSD) for the same set of swept sine input. The amplitude discrepancy observed in the PDS plot can most likely be attributed to the different recording lengths for the RefTek and Terra systems (records extend beyond the 50 second window plotted) 
Comparison of Frequency and Time Domain Data

Terra Technology \& Refraction Technology Data Acquisition Systems
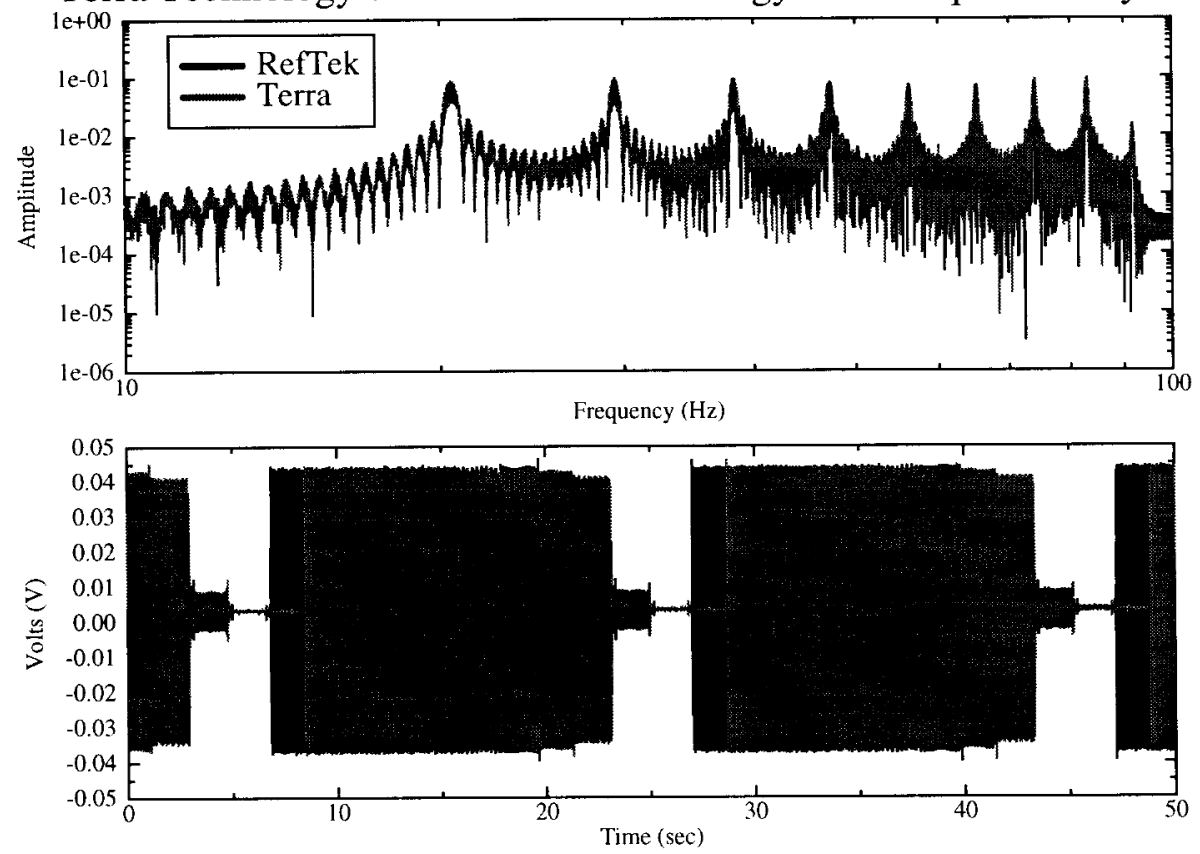

FIGURE 4. Time and frequency domain plots for 20 to $110 \mathrm{~Hz}$ swept sine recordings (amplitude portion of the FFT)

Comparison of Frequency and Time Domain Data

Terra Technology \& Refraction Technology Data Acquisition Systems
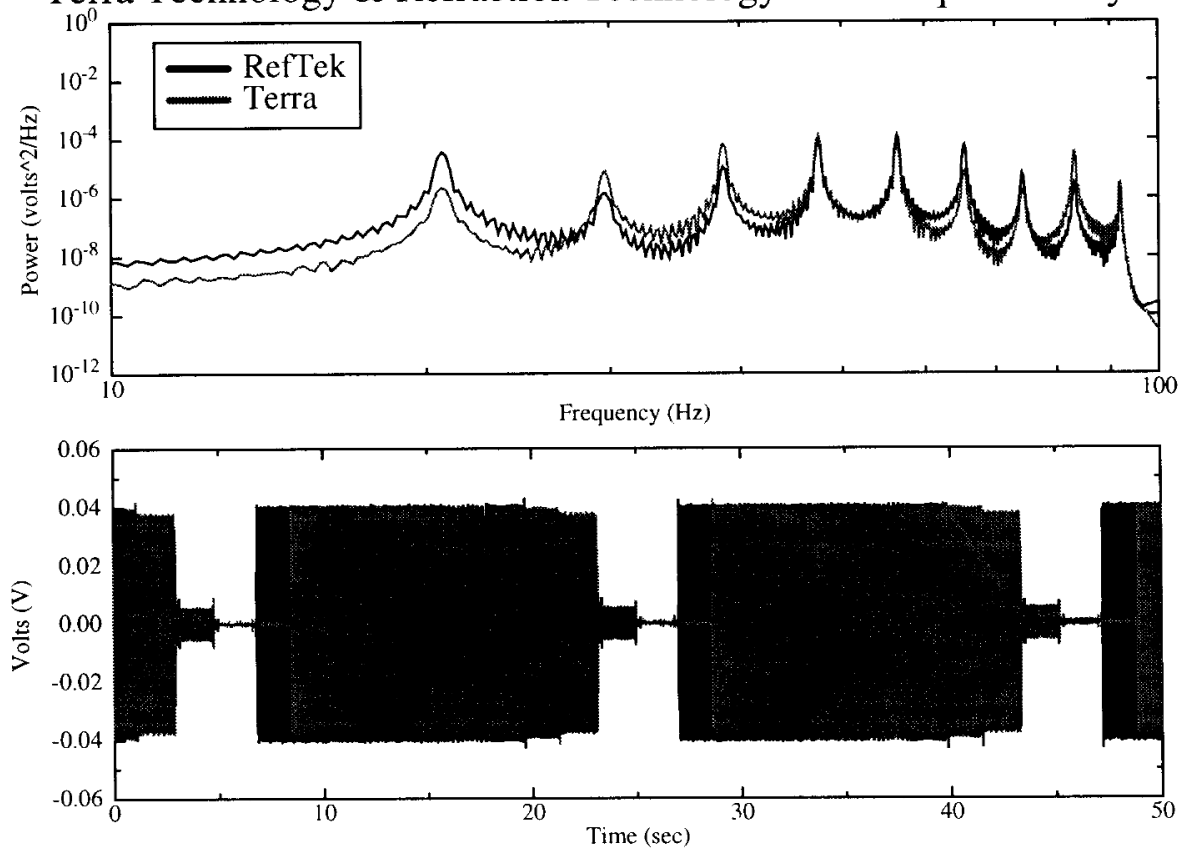

FIGURE 5. Time and frequency domain plots for 20 to $110 \mathrm{~Hz}$ swept sine recordings (PSD) 
Comparison of Frequency and Time Domain Data Terra Technology \& Refraction Technology Data Acquisition Systems
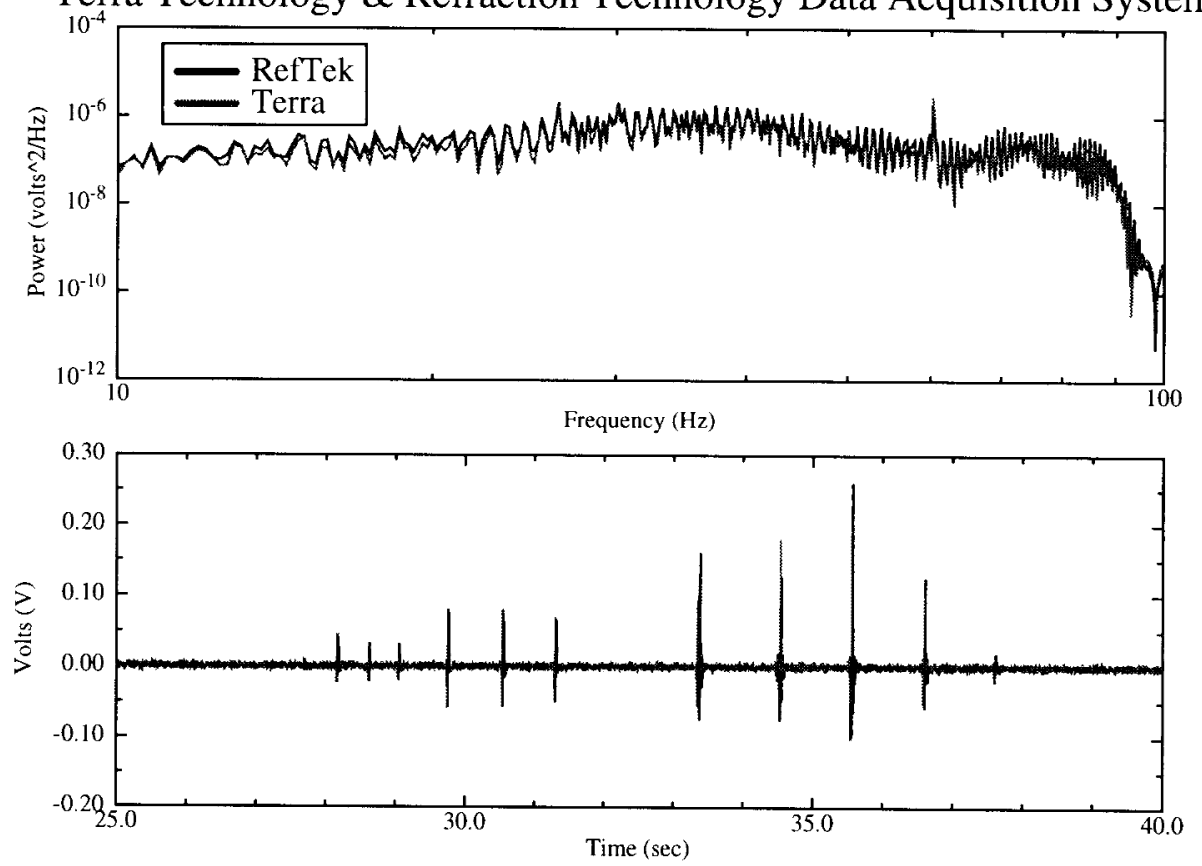

FIGURE 6. Time and frequency domain plots for foot stomp records

Comparison of Frequency and Time Domain Data Terra Technology \& Refraction Technology Data Acquisition Systems
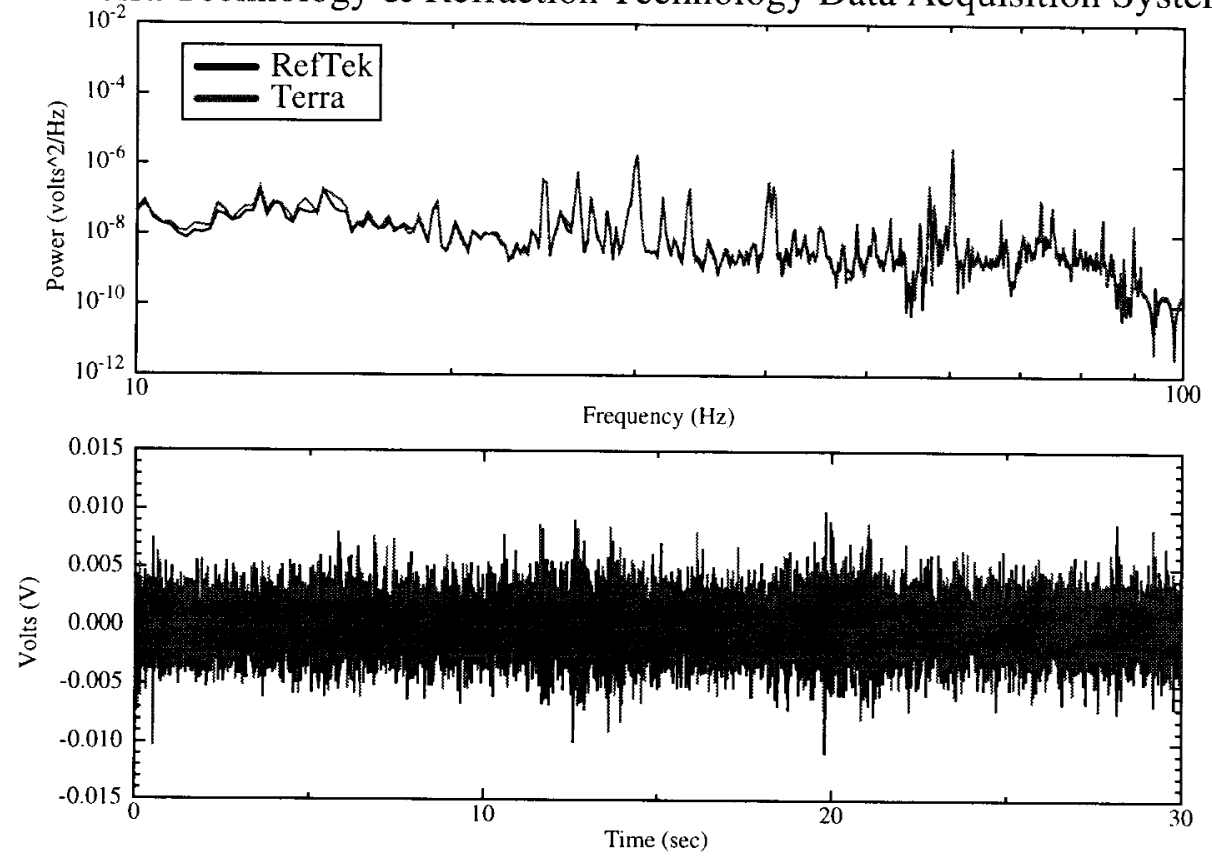

FIGURE 7. Time and frequency domain plots for background noise records 
Appendix A: Connector Diagrams 


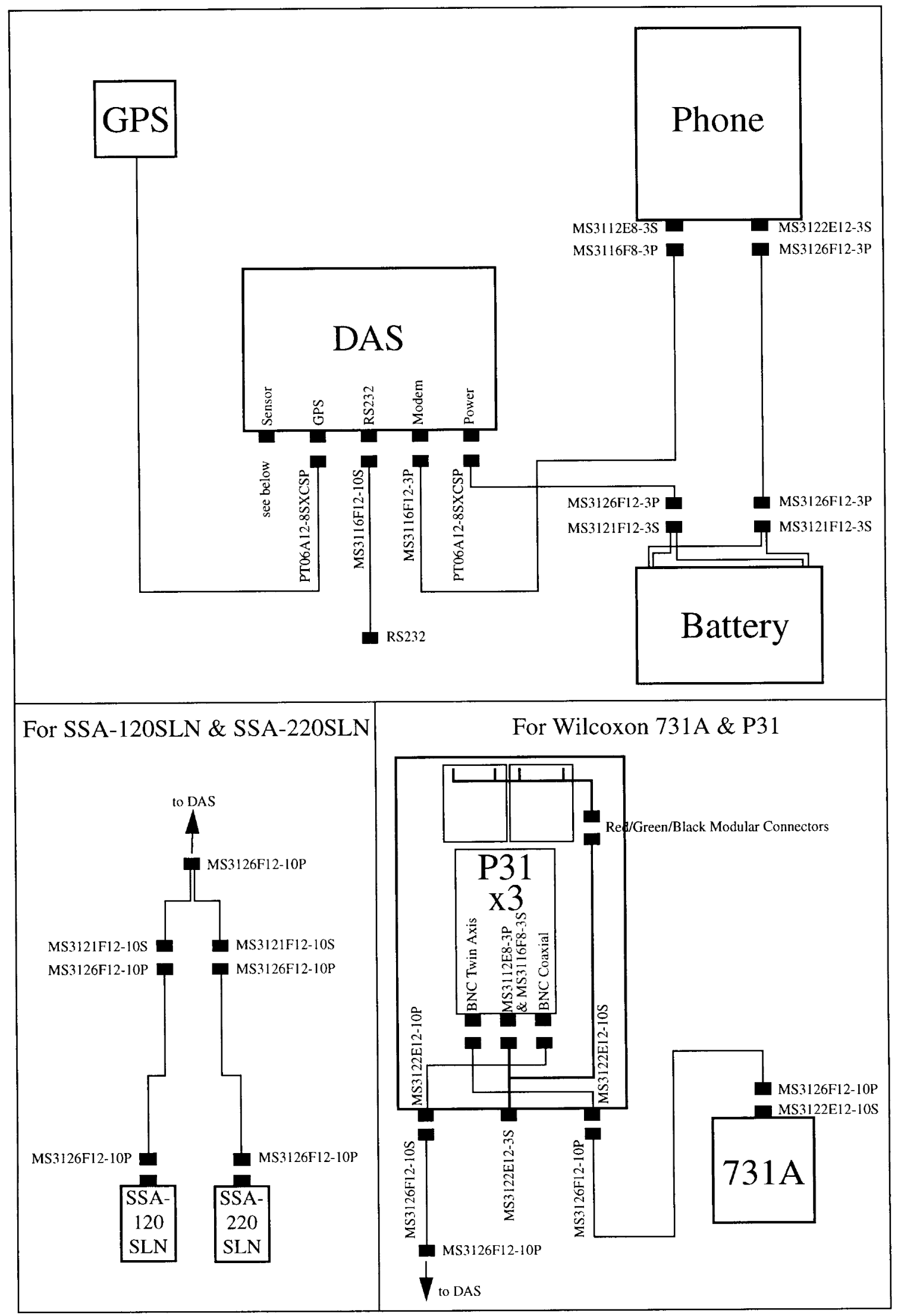




\section{Appendix B: Plans for Wilcoxon 731A Triaxial Enclosure}

Designs by: Carl Boro 


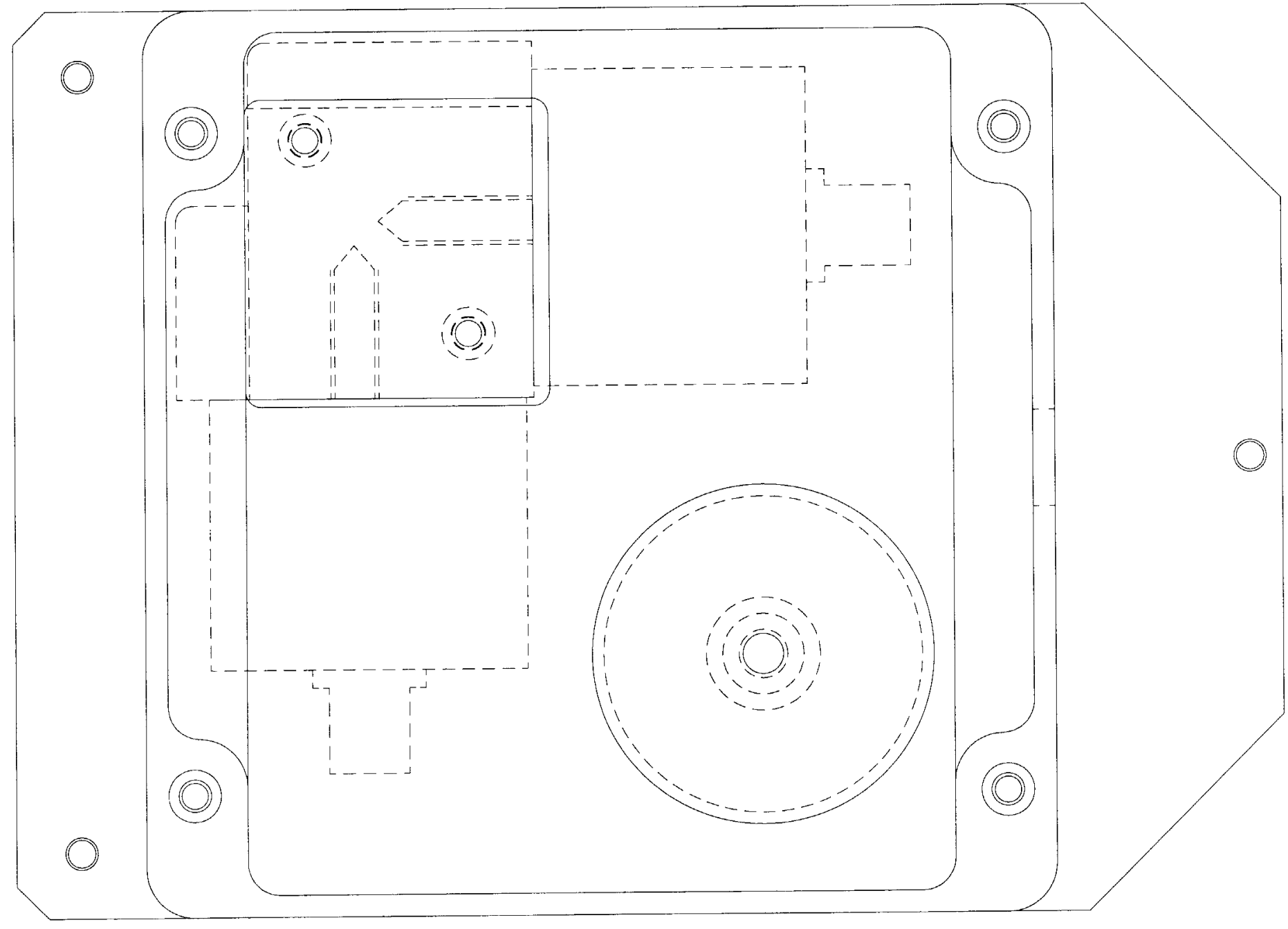

Accelerometer Layout 


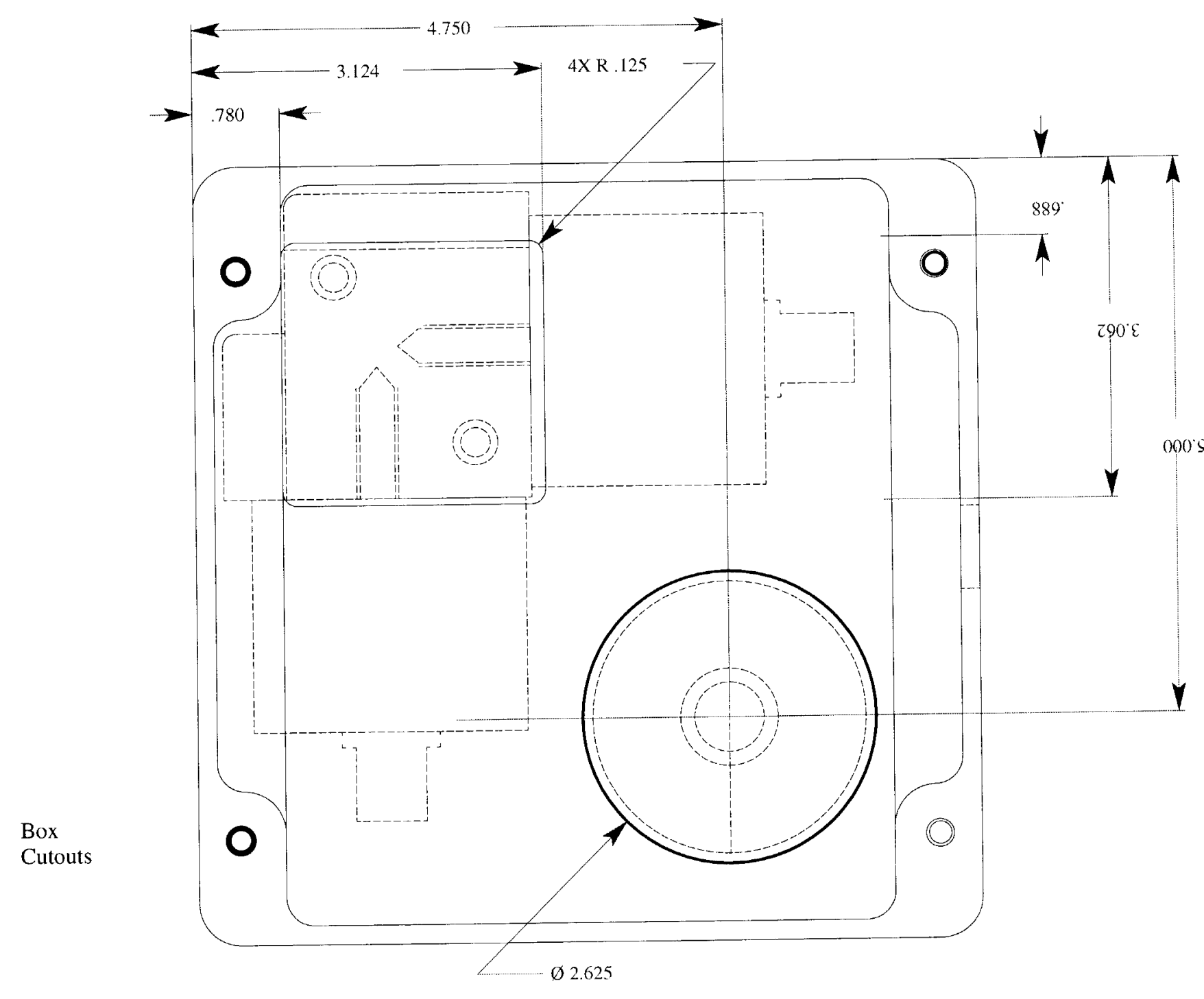




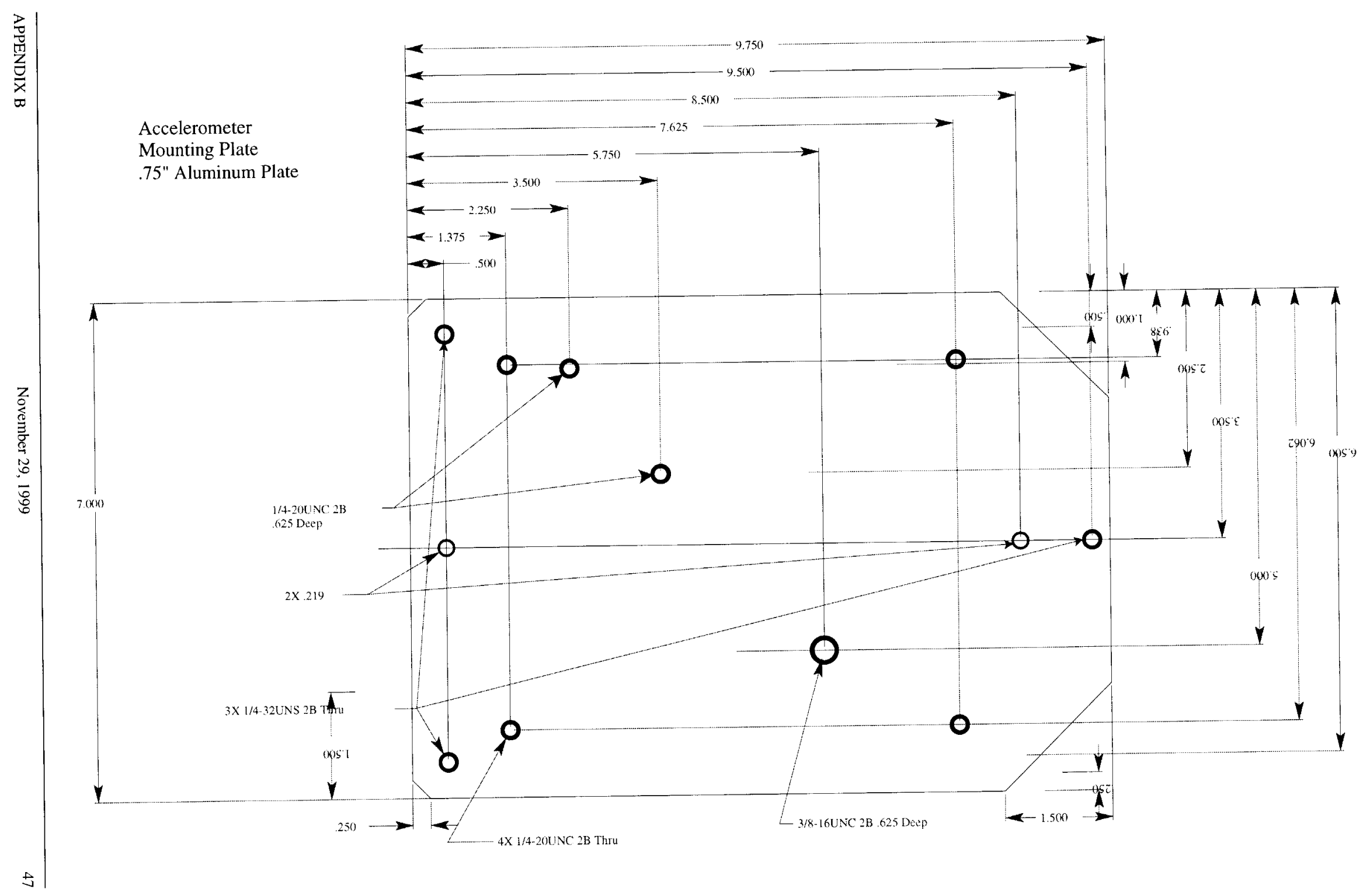




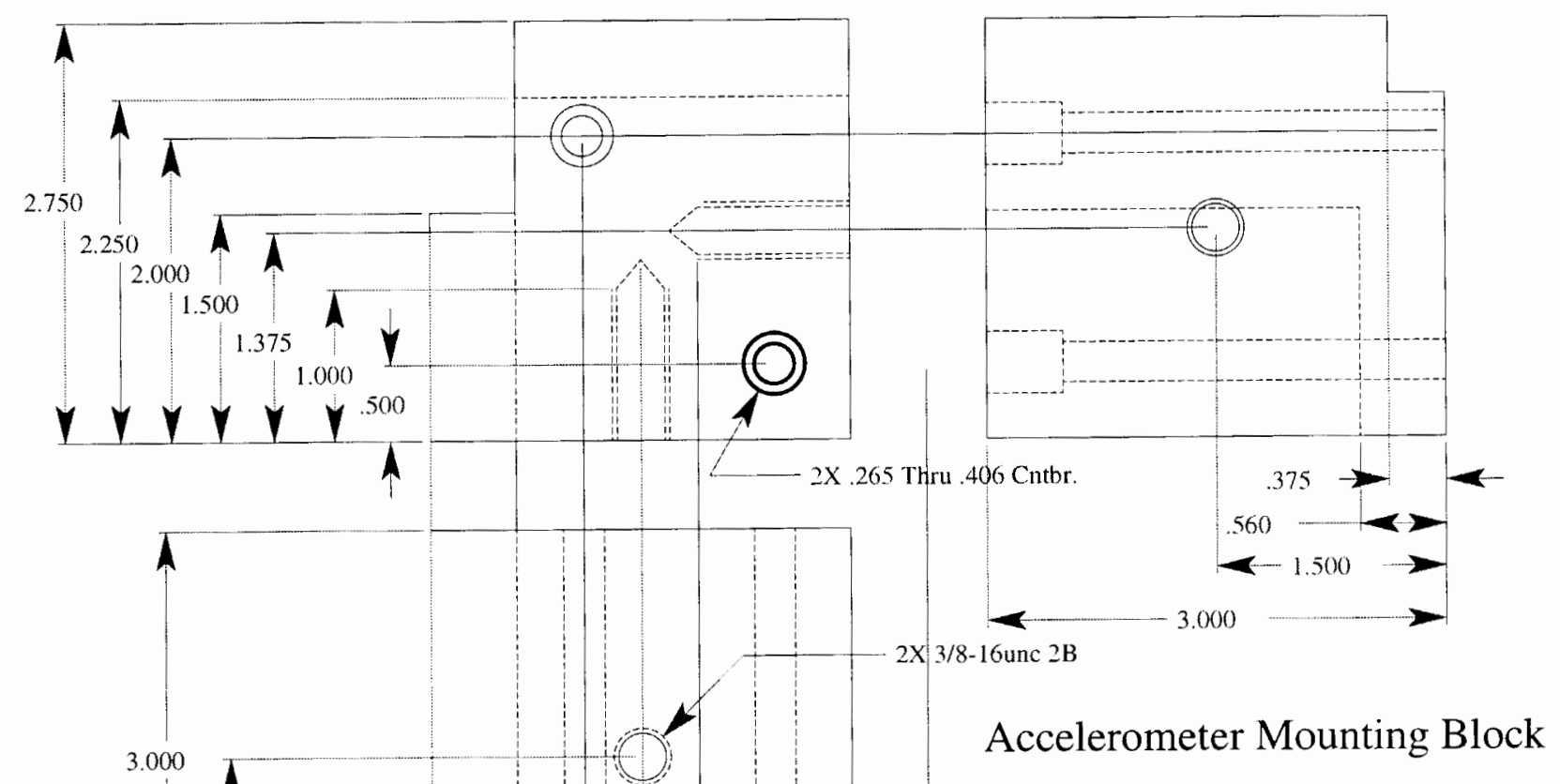




\section{Appendix C: Wiring Diagram for Wilcoxon P31 Amplifier}




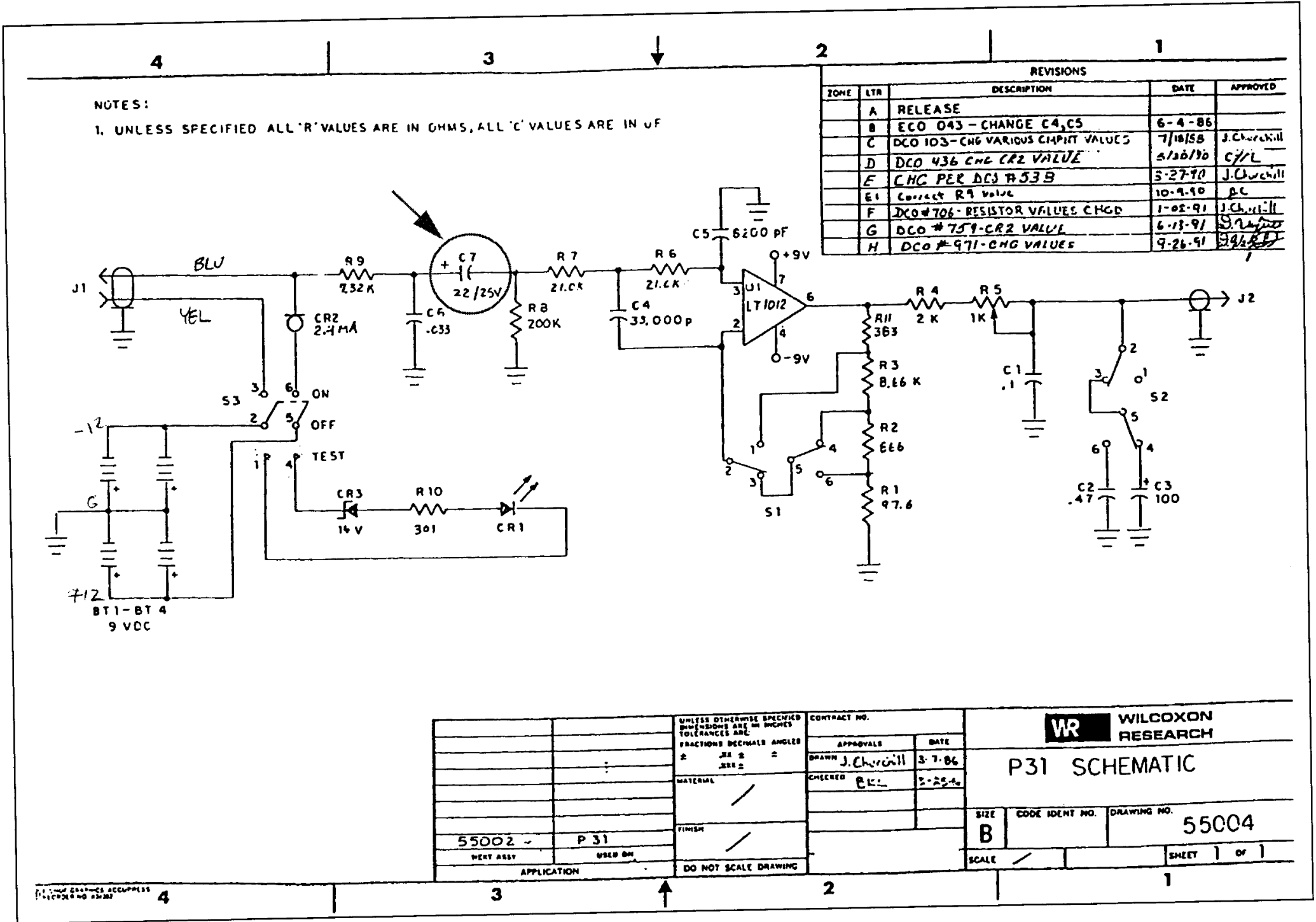

